\title{
The Weakening and Eastward Movement of ENSO Impacts during the Last Glacial Maximum ${ }^{\circ}$
}

\author{
SHANSHAN LIU \\ Institute of Atmospheric Physics, Chinese Academy of Sciences, and University of Chinese Academy of Sciences, \\ Beijing, China \\ DABANG JIANG \\ Institute of Atmospheric Physics, Chinese Academy of Sciences, and CAS Center for Excellence in Tibetan Plateau Earth \\ Sciences, and University of Chinese Academy of Sciences, Beijing, China \\ XIANMEI LANG \\ Institute of Atmospheric Physics, Chinese Academy of Sciences, and CAS Center for Excellence in Tibetan Plateau Earth \\ Sciences, Beijing, China
}

(Manuscript received 27 September 2019, in final form 12 April 2020)

\begin{abstract}
The assumption of a stationary global signal linked to El Niño-Southern Oscillation (ENSO) events is often used in paleo-ENSO proxy data interpretation. This paper attempts to investigate whether the assumption is valid during the last glacial maximum (LGM) over the region $60^{\circ} \mathrm{S}-90^{\circ} \mathrm{N}, 60^{\circ} \mathrm{E}-60^{\circ} \mathrm{W}$. Using four models within phase 3 of the Paleoclimate Modeling Intercomparison Project framework that well reproduce ENSOinduced variabilities, differences from the preindustrial period to LGM in the ENSO-related sea surface temperature pattern and its impacts are investigated. Compared to the preindustrial period, the ENSO impacts are revealed to weaken and shift eastward during the LGM. According to multimodel medians, ENSO impacts on precipitation and near-surface air temperature are attenuated over most regions of concern, with percentage changes in both parameters averaging $-21 \%$ for the whole region; the ENSO-induced PacificNorth America (PNA) teleconnection pattern is weakened, manifested by the $41 \%$ diminished center over the North Pacific and the almost vanished activity centers over the continent. Spatially, there is a zonal contraction of $13^{\circ}$ for the sea surface warming of ENSO, as well as eastward migration over $10^{\circ}$ for the ENSOinduced positive precipitation anomaly center over the tropical Pacific and the PNA teleconnection pattern outside the tropics. The aforementioned changes are linked to the altered climatic background during the LGM, which features a $16^{\circ}$ eastward shift for the Pacific Walker circulation rising branch and a weakened waveguide in the midlatitudes. The results suggest that the hypothesis of stationary ENSO impacts should be applied cautiously to the past.
\end{abstract}

\section{Introduction}

El Niño-Southern Oscillation (ENSO) is a naturally occurring fluctuation that originates in the equatorial Pacific and arises from ocean-atmosphere interactions

Supplemental information related to this paper is available at the Journals Online website: https://doi.org/10.1175/JCLI-D-190728.s1.

Corresponding authors: Dabang Jiang, jiangdb@mail.iap.ac.cn; Xianmei Lang, langxm@mail.iap.ac.cn
(Bjerknes 1969; Neelin et al. 1998; Collins et al. 2010). It provides the dominant source of interannual climate variability and exerts climatic impacts that are felt throughout the world (Trenberth et al. 1998). Over the past decades, ENSO has experienced long-term changes in frequency, amplitude, and spatial pattern (Kim et al. 2014; Yeh et al. 2018). Available observations consistently suggest longer persistence and larger amplitudes of ENSO activities since the late 1970s (An and Wang 2000; Yu and Kao 2007; Kim et al. 2014). The period 1980-2000 is marked by particularly intense ENSO activities (Philander 1983; McPhaden et al. 2006), 
including the 1982/83 and 1997/98 extreme El Niño events that disrupted normal weather and climate patterns, spurred worldwide natural disasters, and caused destructive consequences to ecosystems and human lives on every continent (Cai et al. 2014). Several studies argued that the intensification of ENSO is partially attributed to anthropogenic forcing (An et al. 2008; Zhang et al. 2008), and there is modeling evidence for a more frequent occurrence of extreme El Niño events in response to greenhouse warming (Cai et al. 2014, 2015; Wang et al. 2019; Carréric et al. 2020). Therefore, it is vital to thoroughly understand and better project the evolution of ENSO variability, especially in the future with increasing greenhouse gas emissions and accompanying warming (IPCC 2013). However, a consensus is still lacking about the future behavior of ENSO (Collins et al. 2010; IPCC 2013; Capotondi et al. 2015).

Instrumental records are limited in length that is insufficient to capture the full range of ENSO variability and restrict the assessment of the sensitivity of ENSO to climate change (Lewis and LeGrande 2015; Lu et al. 2018). Proxybased climate reconstructions offer a valuable approach for investigating the history of ENSO under various climate scenarios that have occurred in the past (Tudhope et al. 2001; Cobb et al. 2013). The proxies that document temperature, drought, and oceanic linkages to the ENSO signal involve not only fossil coral (Watanabe et al. 2011), mollusk shells (Emile-Geay et al. 2016), and marine sediments (Rein et al. 2005; Leduc et al. 2009; Ford et al. 2015) in the tropical central and eastern Pacific but also lake sediments (Thompson et al. 2017), speleothem (Chen et al. 2016), tree rings ( $\mathrm{Li}$ et al. 2013), and ice cores (Thompson et al. 2013) collected from remote sensitive sites outside the core ENSO regions. However, researchers have raised concerns that the assumption of a stationary atmospheric teleconnection pattern induced by ENSO, which is the basis of these paleo-ENSO proxies from remote sites, may not be valid when the climate differed from modern times (Merkel et al. 2010; $\mathrm{Lu}$ et al. 2018). There is evidence that the background mean states could modify the climatic responses to ENSO (Bonfils et al. 2015; López-Parages et al. 2015), even in the absence of variations in ENSO itself (Meehl and Teng 2007; Zhou et al. 2014). In this context, the information preserved in paleo-records may involve not only the ENSO evolution but also the difference in ENSO-induced teleconnections from what they are today. Therefore, it is necessary to conduct a direct analysis of the ENSO impacts in the past, and this might be critical for interpreting proxies originating outside of the core ENSO region.

In recent decades, the dynamical processes by which ENSO affects climates have been well documented. In tropical regions, ENSO affects climates via the atmospheric bridge mechanism associated with the Walker circulation (Klein et al. 1999; Alexander et al. 2002; Lau and Nath 2003). During El Niño events, an anomalous warming in the eastern equatorial Pacific sea surface temperature (SST) causes intensified convection; then, the ascending branch of Pacific Walker circulation weakens and shifts eastward from its normal location, the Maritime Continent, further disturbing the Indian and Atlantic Ocean branches (Dai and Wigley 2000; Bayr et al. 2014; Yang et al. 2018). Outside the tropics, the impacts of ENSO mainly arise through the excitation of atmospheric Rossby waves, which propagate following great-circle routes to form the Pacific-North America (PNA) teleconnection pattern in the Northern Hemisphere (Horel and Wallace 1981; Hoskins and Karoly 1981; Wallace and Gutzler 1981) and the Pacific-South America pattern in the Southern Hemisphere (Karoly 1989; Mo and Higgins 1998). These ENSO-driven perturbations of atmospheric circulations induce anomalies in precipitation, temperature, and winds worldwide.

Climate models have been widely used to investigate ENSO variability and its impacts on remote regions (Bonfils et al. 2015; Power and Delage 2018; Yeh et al. 2018). An evaluation of the models from phase 5 of the Coupled Model Intercomparison Project (CMIP5) (Taylor et al. 2012) indicates that the ENSO-related SST pattern in the tropical Pacific Ocean is relatively well simulated when compared to observations (Roy et al. 2018). In addition, the model ensemble is able to yield amplitudes and signs that agree with the observed ENSO precipitation teleconnections (Langenbrunner and Neelin 2013). The aforementioned advances in ENSO theories and climate models make it possible to directly diagnose past ENSO impacts using models. Several studies have focused on the instability of ENSO impacts based on last millennium experiments from phase 3 of the Paleoclimate Modeling Intercomparison Project (PMIP3) under the framework of CMIP5 (Lewis and LeGrande 2015; Brown et al. 2016). In comparison with the last millennium, the Last Glacial Maximum (LGM; approximately 21000 calendar years ago) is a period featuring a more dramatically different climate from today, which may offer more critical insights into the sensitivity of ENSO impacts to climate change. Merkel et al. (2010) investigated the ENSO teleconnections during the LGM using CCSM3 and indicated a weakening compared to the preindustrial period. However, they analyzed only the ENSO-driven features outside the tropics and focused only on the atmospheric circulations and air temperature, and whether their single-model results hold for multiple state-of-the-art models remains an open question.

Based on the above research, the impacts of ENSO on temperature, precipitation, and atmospheric circulations during the LGM are examined using climate 
TABLE 1. Basic information on the PMIP3 models employed in this study. The first run is used if the model has multiple runs. The last 100 years are taken for analysis. The basic information and reference papers of the models are available at https://pcmdi.llnl.gov/mips/ cmip5/. The four models used for calculating the ensemble in the analysis are marked with an asterisk $(*)$. The serial numbers are used in Fig. 5.

\begin{tabular}{|c|c|c|c|c|c|}
\hline \multirow[b]{2}{*}{ Serial No. } & \multirow[b]{2}{*}{ Model ID } & \multirow[b]{2}{*}{ Modeling center (or group) } & \multirow{2}{*}{$\begin{array}{l}\text { Atmospheric horizontal resolution } \\
\text { and number of vertical levels }\end{array}$} & \multicolumn{2}{|c|}{$\begin{array}{c}\text { Length of run } \\
\text { available } \\
\text { online (yr) }\end{array}$} \\
\hline & & & & PI & LGM \\
\hline 1 & CCSM4* & $\begin{array}{l}\text { National Center for Atmospheric } \\
\text { Research, United States }\end{array}$ & $1.25^{\circ} \times \sim 0.9^{\circ}, \mathrm{L} 26$ & 501 & 101 \\
\hline 2 & CNRM-CM5 & $\begin{array}{l}\text { Centre National de Recherches } \\
\text { Météorologiques, France }\end{array}$ & $\sim 1.4^{\circ} \times 1.4^{\circ}, \mathrm{L} 31$ & 850 & 200 \\
\hline 3 & COSMOS-ASO & $\begin{array}{l}\text { Max Planck Institute for Meteorology, } \\
\text { Hamburg, Germany }\end{array}$ & $3.75^{\circ} \times \sim 3.7^{\circ}, \mathrm{L} 19$ & 400 & 600 \\
\hline 4 & FGOALS-g2* & $\begin{array}{l}\text { Institute of Atmospheric Physics, Chinese } \\
\text { Academy of Sciences, China }\end{array}$ & $\sim 2.8^{\circ} \times 3^{\circ}-6^{\circ}, \mathrm{L} 26$ & 700 & 100 \\
\hline 5 & GISS-E2-R* & $\begin{array}{l}\text { NASA Goddard Institute for Space } \\
\text { Studies, United States }\end{array}$ & $2.5^{\circ} \times 2^{\circ} \mathrm{L} 40$ & 1200 & 100 \\
\hline 6 & IPSL-CM5A-LR* & Institut Pierre-Simon Laplace, France & $3.75^{\circ} \times \sim 1.9^{\circ}, \mathrm{L} 39$ & 1000 & 200 \\
\hline 7 & MIROC-ESM & $\begin{array}{l}\text { Japan Agency for Marine-Earth Science } \\
\text { and Technology, Japan }\end{array}$ & $\sim 2.8^{\circ} \times 2.8^{\circ}, \mathrm{L} 80$ & 630 & 100 \\
\hline 8 & MPI-ESM-P & $\begin{array}{l}\text { Max Planck Institute for Meteorology, } \\
\text { Hamburg, Germany }\end{array}$ & $1.875^{\circ} \times \sim 1.9^{\circ}, \mathrm{L} 47$ & 1156 & 100 \\
\hline 9 & MRI-CGCM3 & Meteorological Research Institute, Japan & $1.125^{\circ} \times \sim 1.1^{\circ}, \mathrm{L} 48$ & 500 & 100 \\
\hline
\end{tabular}

simulations undertaken by PMIP3 models in this study. We focus on the region $60^{\circ} \mathrm{S}-90^{\circ} \mathrm{N}, 60^{\circ} \mathrm{E}-60^{\circ} \mathrm{W}$, where most proxies are located, as summarized by Lu et al. (2018). This paper is structured as follows. Section 2 describes the data and methods. Section 3 provides an assessment of the models. In sections 4 and 5, we examine changes in ENSO impacts and possible mechanisms based on multimodel medians. Section 6 evaluates the intermodel consistency. Section 7 presents a summary and discussion.

\section{Data and methods}

\section{a. Model and observation data}

Monthly mean SST, near-surface air temperature, precipitation, sea level pressure (SLP), and specific humidity, as well as multiple levels of air temperature, geopotential height, zonal wind velocity, and vertical component of velocity in pressure coordinates, are applied in this study. The analysis is based on all available general circulation models that conduct LGM experiments within the PMIP3 framework (Table 1). The median is used to measure the center tendency of multiple models, since this estimator is hardly affected by outliers ( $\mathrm{Li}$ et al. 2012). The preindustrial period is the baseline used for the comparison with LGM. The simulations have been run with predefined stable boundary conditions (Table 2) for at least 500 and 100 years after the spinup period in the preindustrial control and LGM experiments, respectively (Taylor et al. 2011). In this study, the last 100 years are taken to represent the quasi-equilibrium climatic states for the periods being considered. The climate drifts, as indicated by the trend of global annual mean 2-m air temperature, are at least 50 times smaller than climatological differences between the LGM and preindustrial periods. Relative to the preindustrial period, the atmospheric greenhouse gas concentrations assigned to the LGM experiment are reduced by $95 \mathrm{ppm}, 410 \mathrm{ppb}$, and $70 \mathrm{ppb}$ for $\mathrm{CO}_{2}, \mathrm{CH}_{4}$, and $\mathrm{N}_{2} \mathrm{O}$, respectively. In addition, the main boundary conditions for the LGM experiment involve the expansion of ice sheets over the continent and the associated decrease in sea levels. The orbital configurations are slightly changed, resulting in fewer differences in radiative forcing relative to other factors (Berger 1978; Harrison et al. 2016). More information about the models and boundary conditions is provided at http://pmip3.lsce.ipsl.fr/.

The model's capability to simulate the present-day ENSO impacts is assessed using data during the period 1979-2018, including monthly SST from version 1.1 of the Met Office Hadley Centre Sea Ice and SST dataset (HadISST1.1) (Rayner et al. 2003), precipitation from version 2.3 of the Global Precipitation Climatology Project (GPCP) (Adler et al. 2003), the near-surface air temperature, SLP, and geopotential height data from the National Centers for Environment Prediction-Department of Energy (NCEP-DOE) Atmospheric Model Intercomparison Project (AMIP-II) reanalysis (NCEP-2) (Kanamitsu et al. 2002). These data are hereafter referred to as observations for convenience. A linear detrending is applied to the observations to remove the global warming trend 
TABLE 2. PMIP3 boundary conditions for the preindustrial (PI) control and LGM (21 ka BP) experiments as taken from the PMIP3 website: http://pmip3.lsce.ipsl.fr/. The control experiments used atmospheric greenhouse gas concentrations corresponding to the approximate levels in 1750 and the orbital parameters in 1950.

\begin{tabular}{lll}
\hline \hline \multicolumn{1}{c}{ Boundary conditions } & \multicolumn{1}{c}{ PI control } & \multicolumn{1}{c}{ LGM } \\
\hline Orbital parameters & Eccentricity $=0.016724$ & Eccentricity $=0.018994$ \\
& Obliquity $=23.446^{\circ}$ & Obliquity $=22.949^{\circ}$ \\
& Periapsis $-180^{\circ}=102.04^{\circ}$ & Periapsis $-180^{\circ}=114.42^{\circ}$ \\
Solar constant & $1365 \mathrm{~W} \mathrm{~m}{ }^{-2}$ & As in PI control \\
Date of vernal equinox & $1200 \mathrm{UTC} 21 \mathrm{Mar}$ & As in PI control \\
Greenhouse gases & $\mathrm{CO}_{2}=280 \mathrm{ppm}$ & $\mathrm{CO}_{2}=185 \mathrm{ppm}$ \\
& $\mathrm{CH}_{4}=760 \mathrm{ppb}$ & $\mathrm{CH}_{4}=350 \mathrm{ppb}$ \\
& $\mathrm{N}_{2} \mathrm{O}=270 \mathrm{ppb}$ & $\mathrm{N}_{2} \mathrm{O}=200 \mathrm{ppb}$ \\
Vegetation & Fixed at present state in coupled & As in PI control \\
& atmosphere-ocean or interactive in & \\
Ice sheets & atmosphere-ocean-vegetation models & Ice sheet extent and sea level changes as \\
& Modern & described on PMIP3 website \\
Topography and coastlines & & Land-sea mask and elevation changes as \\
& Modern & described on PMIP3 website \\
\hline
\end{tabular}

(Yeh et al. 2018). The data from both observations and simulations are aggregated to a $1^{\circ}$ latitude $\times 1^{\circ}$ longitude grid using bilinear interpolation.

\section{b. Identification of ENSO impacts}

This study considers the December-February (DJF) season, the peak season of the ENSO event, and its impacts (Rasmusson and Carpenter 1982); this seasonality can be well captured by PMIP3 models (Figs. S1 and $\mathrm{S} 2$ in the online supplemental material). The impacts induced by only canonical or eastern Pacific ENSO phenomenon (Capotondi et al. 2015) are analyzed. The area average of DJF-mean SST anomalies over $5^{\circ} \mathrm{N}-5^{\circ} \mathrm{S}$, $170^{\circ}-120^{\circ} \mathrm{W}$, referred to as the Niño-3.4 SST index (Rasmusson and Carpenter 1982), is taken to represent the SST variability linked to canonical ENSO. The Niño-3.4 SST index is nearly identical to the principal component time series associated with the leading empirical orthogonal function mode of the Pacific region $30^{\circ} \mathrm{N}-30^{\circ} \mathrm{S}$, and their correlation coefficient is $0.94-0.99$ for both the preindustrial period and the LGM. The ENSO impacts are identified by regressing simultaneous variable fields onto the Niño-3.4 index, and a larger absolute value of the regression coefficient means a greater ENSO impact (García-Serrano et al. 2017; Yeh et al. 2018). Statistical significance is assessed with the two-tailed Student's test at the $95 \%$ confidence level.

\section{Assessment of models}

\section{a. Model selection}

The models whose preindustrial simulations are close to observations are selected for the following analysis, toward an assurance that the employed models are skillful in simulating ENSO-related anomalies. Here, we compare simulations and observations according to the method provided by Taylor (2001), where the degree of the correspondence for two fields is determined by the spatial correlation coefficient, normalized standard deviation, and normalized centered root-mean-square difference. If the first two statistics are close to 1 , and therefore the third is close to 0 , the simulation effectively matches the observation. The ENSO-induced anomalies in SST, precipitation, near-surface air temperature, SLP, and geopotential height at $200 \mathrm{hPa}$ are all evaluated. The comparisons are conducted based on data at all grids over the region considered here $\left(60^{\circ} \mathrm{S}-90^{\circ} \mathrm{N}, 60^{\circ} \mathrm{E}-60^{\circ} \mathrm{W}\right)$. For all these comparisons, the Taylor diagram (Fig. 1) illustrates that the three statistics of individual models fall in the ranges of $0.13-0.88,0.50-1.56$, and $0.49-1.51$, respectively, indicating that there are still models that fail to reasonably capture the features of the spatial pattern and variation amplitude of the observed ENSO impacts. In comparison, COSMOS-ASO and MIROC-ESM are the worst at simulating all the variables, even in reproducing the ENSO-related SST anomalies. As such, two criteria are set for model selections: 1) the normalized standard deviation falls within the range 0.6-1.4, and 2) the normalized centered root-mean-square difference is less than 1.2. The models whose comparison for any variable does not conform to the criteria are excluded. In addition, the geographical distribution of ENSO impacts for individual models are exhibited in the supplemental material (Figs. S3-S7). It is shown that CNRM-CM5 cannot reproduce the ENSO-related PNA teleconnection pattern (Figs. S6 and S7) and associated temperature anomalies (Fig. S5) in the Northern 


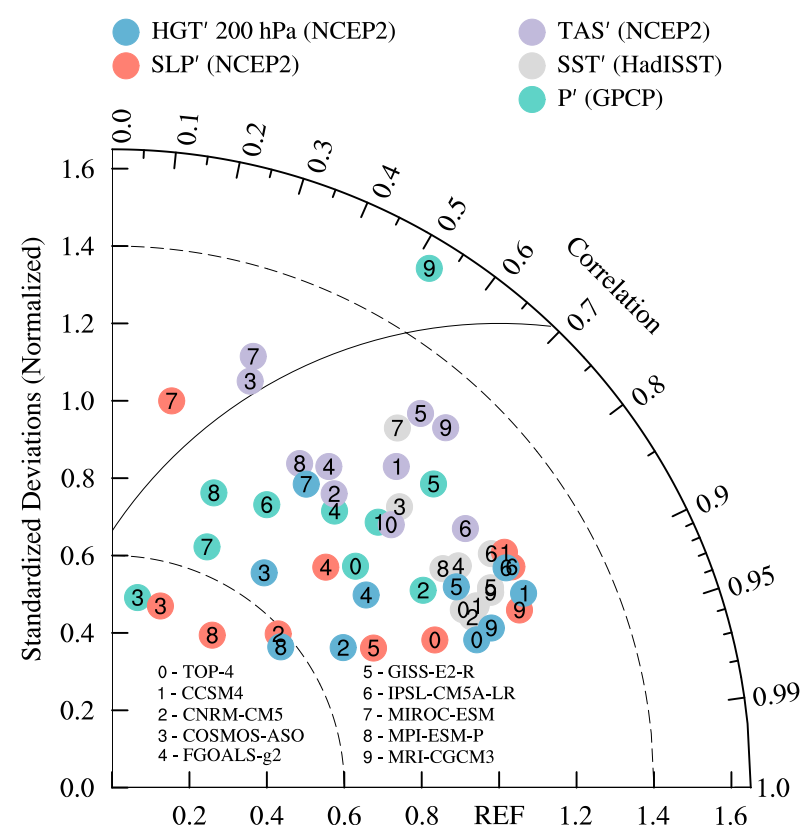

FIG. 1. Taylor diagram (Taylor 2001) for displaying normalized pattern statistics of the DJF Niño-3.4 index-regressed anomalies between the PMIP3 preindustrial (hereafter referred to as PI in the figure captions) control experiments and observations during the period 1979-2018. The calculation is based on all grids over the region $60^{\circ} \mathrm{S}-90^{\circ} \mathrm{N}, 60^{\circ} \mathrm{E}-60^{\circ} \mathrm{W}$. The gray, green, purple, red, and blue dots denote comparisons for anomalies in SST, precipitation $(P)$, near-surface air temperature (TAS), SLP, and 200-hPa geopotential height (HGT) in DJF, respectively. The points marked by TOP-4 represent the medians of the four good models (CCSM4, FGOALS-g2, GISS-E2-R, and IPSL-CM5A-LR). The radial distance from the origin is the normalized standard deviation; the spatial correlation coefficient between a model and the reference is expressed by the azimuthal position; and the normalized centered root-mean-square difference between a model and the reference is their distance apart.

Hemisphere, so this model is not taken here. Ultimately, four models, CCSM4, FGOALS-g2, GISS-E2-R, and IPSL-CM5A-LR, are selected as the good models. The three statistics for the median fields of these four models follow the order $0.73-0.88,0.84-1.04$, and $0.49-0.71$, indicating that the multimodel medians substantially approximate observations and outperform individual models. Accordingly, the multimodel median of the four good models is emphasized in the following analysis.

\section{b. Comparison of the main features of ENSO impacts}

The multimodel medians of the selected models are compared to the observations in terms of spatial structures of ENSO-related anomalies. Key features for the observed ENSO SST map (Fig. 2a) include an anomalous warming across the central-eastern equatorial Pacific, flanked by an anomalous cold surface extending from the far western tropical Pacific to the west coasts of (a) $\mathrm{SST}^{\prime}$ HadISST (1979-2018)

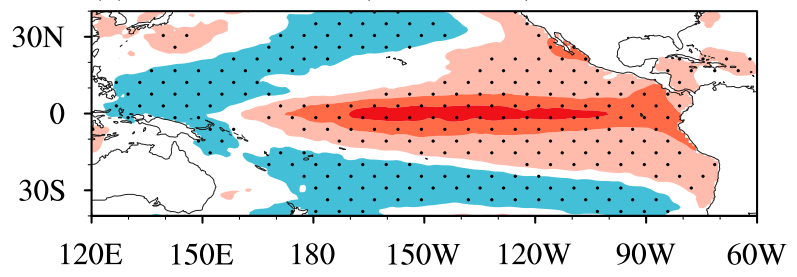

(b) SST' LGM (shading) \& PI (contour)

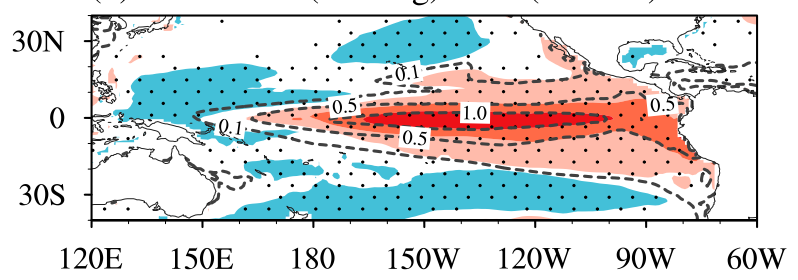

(c) $\triangle \mathrm{SST}^{\prime}(\mathrm{LGM}-\mathrm{PI})$

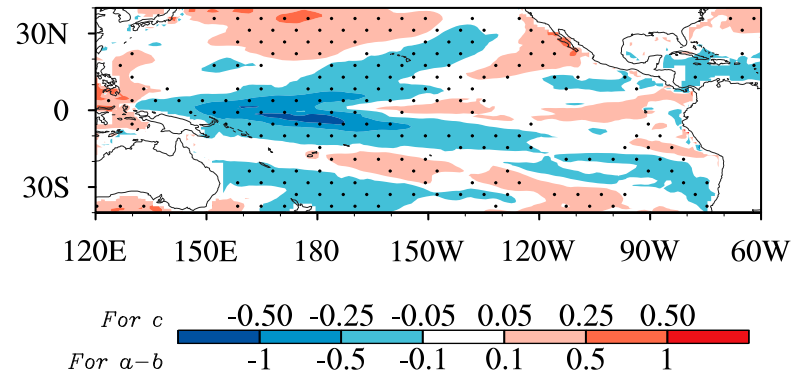

(d) $5 \mathrm{~S}-5 \mathrm{~N}$ mean along equator

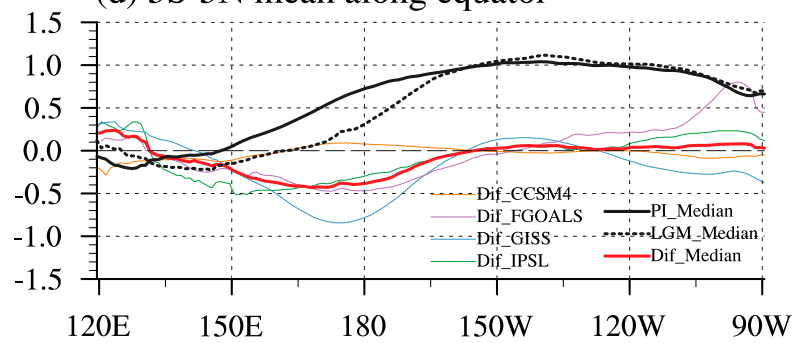

FIG. 2. Regressed anomalies in DJF SST against the DJF Niño-3.4 index (SST'; unit: ${ }^{\circ} \mathrm{C} \quad{ }^{\circ} \mathrm{C}^{-1}$ ) using data from (a) HadISST and (b) multimodel medians of PMIP3 for the LGM and PI control experiments, (c) the LGM minus PI difference $\left(\Delta \mathrm{SST}^{\prime}\right)$, and (d) the $5^{\circ} \mathrm{S}-5^{\circ} \mathrm{N}$ mean of $\Delta \mathrm{SST}^{\prime}$ (colored lines) or $\mathrm{SST}^{\prime}$ (gray lines) along the equator. Stippling indicates regions where the regression coefficient is statistically significant at the $95 \%$ confidence level in (a), and where at least three out of four models agree on the sign in (b) and (c).

North and South America in a horseshoe-like fashion. At low latitudes, the ENSO-induced precipitation anomalies [Fig. 3a(1)] are above normal from the eastern tropical Pacific to the Solomon Islands, with values over $1 \mathrm{~mm}$ day ${ }^{-1}{ }^{\circ} \mathrm{C}^{-1}$ in the $160^{\circ} \mathrm{E}-120^{\circ} \mathrm{W}$ region, and below normal over the western Pacific, the Maritime Continent, and northern South America. The peak response of precipitation is located far to the west of the peak SST 
(a1) P' GPCP \& $\overline{\mathrm{V}^{\prime}}$ NCEP2 (1979-2018)

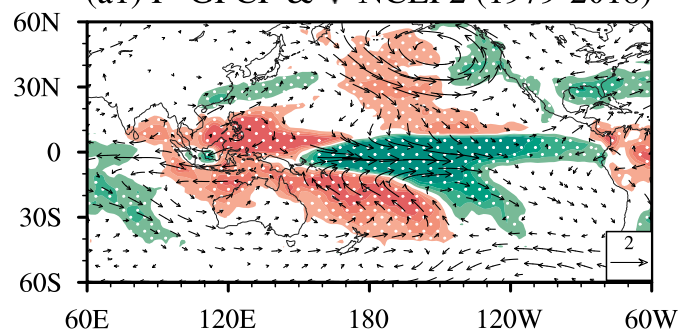

(b1) P' PI

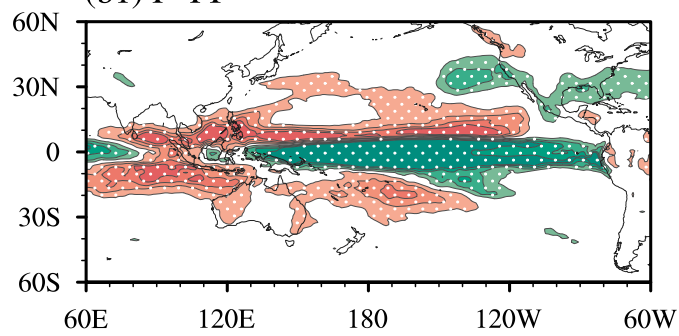

(c1) $\mathrm{P}^{\prime}$ LGM

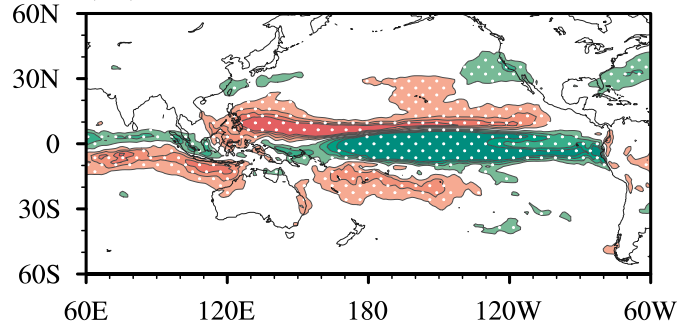

(d1) $\Delta \mathrm{P}^{\prime} \Delta \overline{\mathrm{V}}^{\prime}$ (LGM-PI)

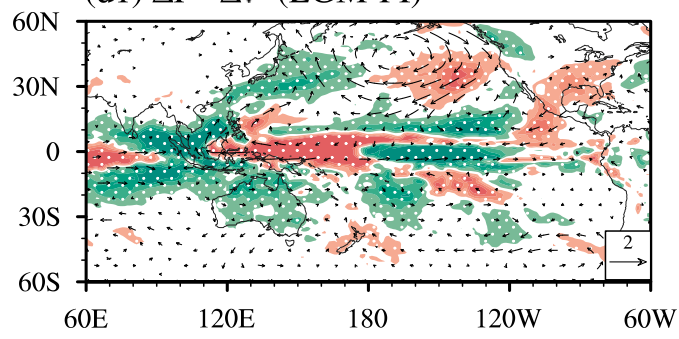

(a2) TAS' NCEP2 (1979-2018)

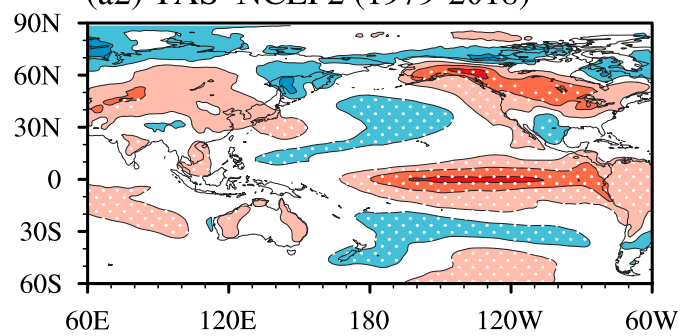

(b2) TAS' PI

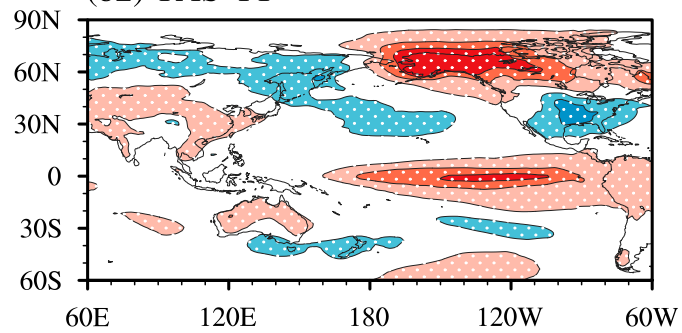

(c2) TAS' LGM

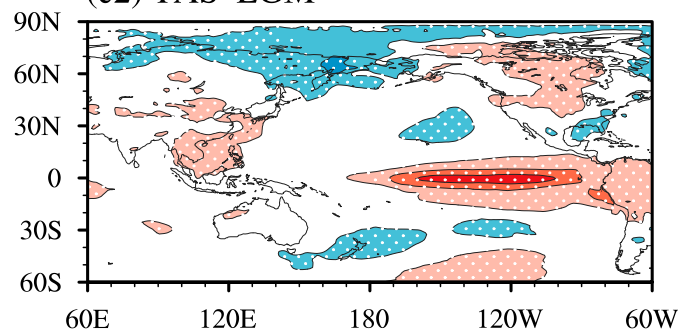

(d2) $\triangle \mathrm{TAS}^{\prime}$ (LGM-PI)

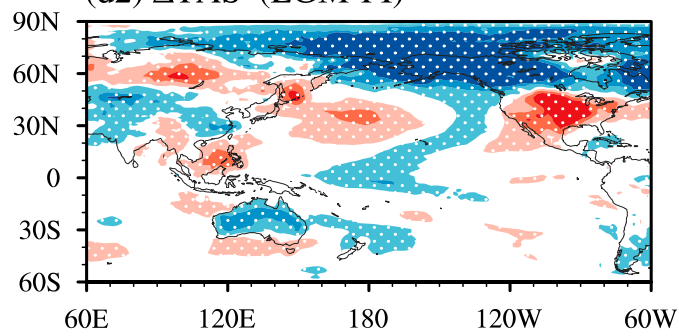

For $d$

For $a-c$

FIG. 3. Regressed anomalies of precipitation $\left(P^{\prime}\right.$; unit: $\mathrm{mm}$ day $\left.{ }^{-1}{ }^{\circ} \mathrm{C}^{-1}\right)$ or near-surface air temperature $\left(\mathrm{TAS}^{\prime}\right.$; unit: ${ }^{\circ} \mathrm{C}^{\circ} \mathrm{C}^{-1}$ ) in DJF onto the DJF Niño-3.4 index using data from (a) observations and multimodel medians for the (b) PI control and (c) LGM experiments, and (d) LGM minus PI differences ( $\Delta P^{\prime}$ or $\left.\Delta \mathrm{TAS}^{\prime}\right)$. Stippling indicates regions where the regression coefficient is statistically significant at the $95 \%$ confidence level in (a) and where at least three out of four models agree on the sign in (b)-(d). The wind vectors in [a(1)] and [d(1)] are at $850 \mathrm{hPa}$.

anomaly position because the climatological cool condition with descending motion impedes convection in the eastern equatorial Pacific. The near-surface air in the core ENSO region is directly warmed by anomalous sea surface warming, with air temperature anomalies higher than $0.6^{\circ} \mathrm{C}^{\circ} \mathrm{C}^{-1}$ in near-equatorial regions to the east of $170^{\circ} \mathrm{W}$ [Fig. 3a(2)]. In northern Australia and northern
South America, the air warming is linked to deficient precipitation and could be attributed to the implied deficits in evaporation and cloudiness, which affect the surface heat budget (Schneider et al. 2009). Outside the tropics, there are positive anomalies of precipitation along the west coast and southern tier of the United States and negative anomalies in the North Pacific 
[Fig. 3a(1)]; warmer and cooler conditions are found over northern and southern North America, respectively [Fig. 3a(2)], and these characteristics result from the ENSO-related PNA pattern (Wallace and Gutzler 1981; Trenberth et al. 1998).

In comparison with the observations, the multimodel median fields of the selected models [Figs. 2b, 3b(1), and $3 \mathrm{~b}(2)]$ are able to capture the aforementioned major elements of the ENSO impacts, although specific regional differences exist. For example, the simulated SST anomalies over the eastern equatorial Pacific are narrower in the meridional direction and extend $6^{\circ}$ farther west (Fig. 2b). Correspondingly, there is also a too-farwest extension of the positive precipitation anomalies, even reaching Papua New Guinea [Fig. 3b(1)]. In the extratropical region, the responses of air temperature over northern North America extend farther northward and westward [Fig. 3b(2)]. These systematic errors are common problems in current climate models, and their causes are still unresolved (Bayr et al. 2019). As such, this work focuses mainly on the large-scale changes in ENSO impacts, not detailed local characteristics.

\section{Changes in ENSO impacts}

\section{a. ENSO SST pattern}

Compared to the preindustrial period, the median fields reveal that the ENSO-induced warming in Pacific SST contracts eastward (Fig. 2b) and the associated amplitude in its west prominently weakens, while there is little change in the east (Fig. 2c). The profile of the $5^{\circ} \mathrm{S}-5^{\circ} \mathrm{N}$ mean of SST anomalies along the equator (Fig. 2d) indicates that the weakened amplitudes occur mainly between $150^{\circ} \mathrm{E}$ and $150^{\circ} \mathrm{W}$, with a percentage value of $-41 \%$ for the multimodel median. In addition, based on the western part of the profile, we show that the zonal distance of contraction is $13^{\circ}$ as measured using the average difference of longitudes for positions where values on the profile equal $0.1^{\circ}, 0.2^{\circ}$, $\ldots, 1.0^{\circ} \mathrm{C}^{\circ} \mathrm{C}^{-1}$.

\section{b. Precipitation and near-surface air temperature}

In the median field of precipitation [Figs. 3b(1)-3d(1)], the absolute value of regression coefficients over all grids considered here averages 0.23 and $0.29 \mathrm{~mm}_{\text {day }}{ }^{-1}{ }^{\circ} \mathrm{C}^{-1}$ during the LGM and preindustrial period, respectively. Such changes indicate an attenuated ENSO impact on the precipitation variability. Spatially, the LGM minus the preindustrial period differences in ENSO-driven precipitation anomalies are not homogeneous. Along the Pacific equator, the difference is negative west of the date line, corresponding to the change in SST, and positive to the east even in the absence of a change in ENSO-driven SST anomalies. Such a change represents an eastward shift of the precipitation response. Here, we define the center longitude of the positive precipitation response as the average over all amplitude-weighted longitudes where the regression coefficients exceed the median value in the region $5^{\circ} \mathrm{S}-5^{\circ} \mathrm{N}, 130^{\circ} \mathrm{E}-80^{\circ} \mathrm{W}$. In the multimodel median, the center is located at $173^{\circ} \mathrm{W}$ during the preindustrial period and moves $15^{\circ}$ eastward during the LGM. Further, the changes in Pacific perturbation spread along the Walker circulation into other tropical regions, leading to weakened impacts of ENSO over the Indian Ocean, western Pacific, and northern Australia. For extratropical regions, including the West Coast and southern tier of the United States, the ENSOdriven precipitation anomalies weaken and shift eastward over $10^{\circ}$.

For near-surface air temperature [Figs. 3b(2)-3d(2)], the multimodel medians suggest that the absolute value of regression coefficients over the whole area averages $0.22^{\circ} \mathrm{C}^{\circ} \mathrm{C}^{-1}$ during the LGM, $21 \%$ below the preindustrial period, indicating that the linkages between ENSO and near-surface air temperature are diminished. This diminishment holds for all regions of concern. Specifically, the warming response in the equatorial Pacific contracts $10^{\circ}$ eastward, with the amplitude between $160^{\circ} \mathrm{E}$ and $160^{\circ} \mathrm{W}$ being $33 \%$ lower than that during the preindustrial period, caused directly by the contraction of the ENSOdriven sea surface warming. Over northern Australia, the anomalous warming of over $0.2^{\circ} \mathrm{C}^{\circ} \mathrm{C}^{-1}$ during the preindustrial period almost vanishes in the LGM, which could be attributed to a smaller ENSO-related decrease in evaporation and cloudiness as implied by the smaller ENSO-induced deficit in precipitation than in the preindustrial period [Fig. 3d(1)]. Over higher latitudes, the centers of the anomalous warming extending from Alaska to western Greenland and the cooling over the southern United States move $20^{\circ}$ and $11^{\circ}$ to the east, respectively, and their peak amplitudes are weakened, with percentage values both being approximately $-60 \%$.

\section{Possible mechanisms}

\section{a. In the tropical Pacific}

\section{1) CAuses For EASTWARD Displacement of POSITIVE PRECIPITATION ANOMALIES}

According to the moisture budget equation, the variation in precipitation is determined by both moisture and circulation (Held and Soden 2006). As indicated by previous studies (Huang and Xie 2015), through a simplification of the moisture budget function, the change in 
the ENSO-induced variability of tropical precipitation can be decomposed as follows:

$$
\Delta P^{\prime} \sim-\left(\Delta q \times \omega^{\prime}+q \times \Delta \omega^{\prime}\right),
$$

where $\Delta$ represents the change between two periods; the prime denotes the departure of variable from the climatological mean state (i.e., regression coefficients upon the Niño-3.4 index); $P$ and $q$ indicate precipitation and near-surface specific humidity, respectively; and $\omega$ indicates the vertical component of velocity at $500 \mathrm{hPa}$, which is a rough representative of tropical convective activity. The term $-\Delta q \times \omega^{\prime}$ is regarded as the thermodynamic component that measures the contribution of background moisture changes. During the LGM, the climatological specific humidity decreases and thus suppresses the ENSO-induced anomalies of precipitation (Fig. 4a). However, the effect of specific humidity is limited when compared to the dynamic component $-q \times \Delta \omega^{\prime}$ (Fig. $4 \mathrm{~b}$ ), whose spatial pattern is almost the same as the structure of tropical $\Delta P^{\prime}$ (Fig. 3d1). Therefore, the change in ENSO-induced variability of vertical motion is the major factor that ultimately leads to the difference in ENSO precipitation variability in the tropics. The spatial pattern of $-q \times \Delta \omega^{\prime}$ is dominated by the altered ENSO-induced circulation anomaly $\Delta \omega^{\prime}$ because of the stronger spatial variation in $\Delta \omega^{\prime}$, so there is a strong similarity between $\Delta P^{\prime}$ (Fig. 4c) and $\Delta \omega^{\prime}$ (Fig. $4 \mathrm{~d}$ ).

Previous studies have demonstrated a close linkage between the background Pacific Walker circulation versus the spatial structure and magnitude of ENSOinduced precipitation variability in the tropical Pacific. Generally, a weakened descending branch of the Pacific Walker circulation could suppress the convection barrier in the tropical eastern Pacific and ultimately intensify the precipitation response during warm events (Bonfils et al. 2015; Huang 2016; Sohn et al. 2019). In addition, it has been noticed that a too-westward position of the Pacific rising branch could shift the high convection responses westward (Bayr et al. 2019). Likewise, based on results from five models, including CNRM5, which performs well in the tropics, our analysis demonstrates a strong linear relationship between changes in the mean-state rising branch and ENSOinduced convection anomalies (Fig. 5). Specifically, the correlation coefficients of the longitude of the mean-state rising branch movement versus positional differences in $\omega^{\prime}$ and $P^{\prime}$ centers and the associated differences in their amplitudes, including negative $\Delta \omega^{\prime}$ and positive $\Delta P^{\prime}$ over the east region, and positive $\Delta \omega^{\prime}$ and negative $\Delta P^{\prime}$ over the west, are all statistically significant at the $95 \%$ confidence level.
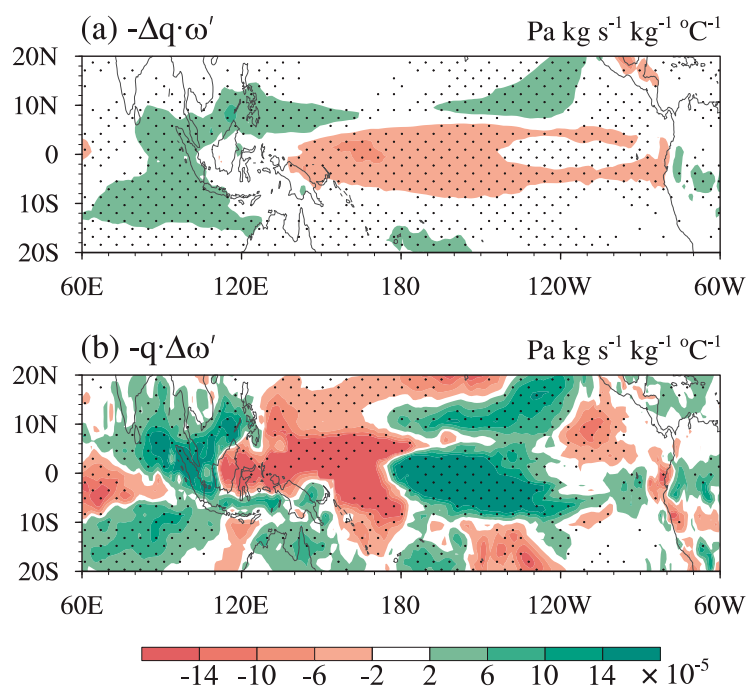

(c) $5 \mathrm{~S}-5 \mathrm{~N}$ mean $\mathrm{P}^{\prime}$ or $\Delta \mathrm{P}^{\prime}$

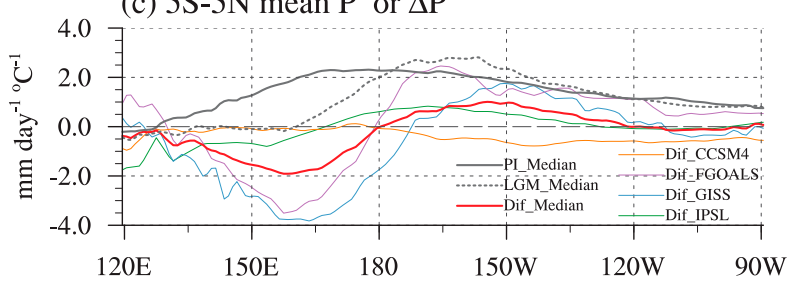

(d) $5 \mathrm{~S}-5 \mathrm{~N}$ mean $\omega^{\prime}$ or $\Delta \omega^{\prime}$ at $500 \mathrm{hPa}$

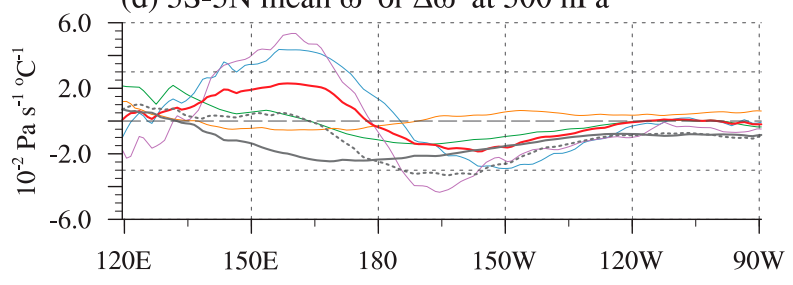

FIG. 4. Spatial distributions of (a) thermodynamic and (b) dynamic components of changes in regressed anomalies of DJF precipitation against the DJF Niño-3.4 index $\left(\Delta P^{\prime}\right)$, as well as $5^{\circ} \mathrm{S}-$ $5^{\circ} \mathrm{N}$ means of regressed anomalies of DJF (c) precipitation and (d) vertical pressure during the PI or LGM ( $P^{\prime}$ and $\omega^{\prime}$; gray lines), or LGM minus PI differences ( $\Delta P^{\prime}$ and $\Delta \omega^{\prime}$; colored lines) along the equator. Stippling in (a) and (b) indicates that at least three out of four models agree on the sign.

During the LGM, the multimodel median indicates a $16^{\circ}$ migration of the mean-state rising branch to the east (Fig. 6a), qualitatively in agreement with previous simulations (Tian and Jiang 2020). Such an eastward migration is accompanied by suppressed vertical motion over the Maritime Continent and intensified motion over the western equatorial Pacific (Fig. 6a), which might be attributed to the exposure of the Sunda Shelf due to a lower sea level (DiNezio et al. 2011) and the change in the hydrological cycle in response to tropical mean cooling, as an opposite condition to the climate warming (Held and Soden 2006; Vecchi and Soden 2007; 


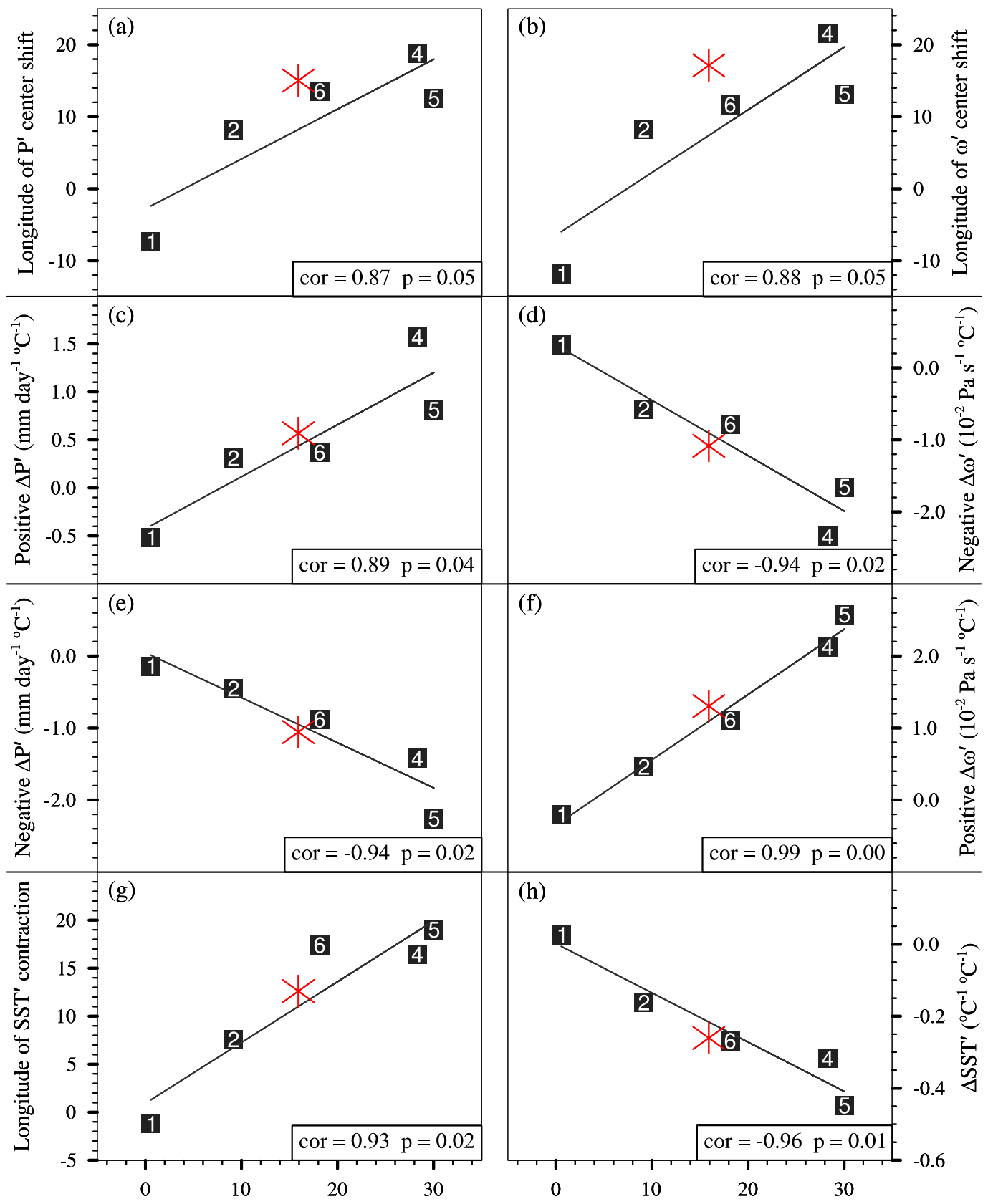

Longitude of PWC rising branch movement

FIG. 5. The relationship between the longitude of the movements of the background Pacific Walker circulation (PWC) rising branch in DJF vs LGM minus PI differences in DJF Niño-3.4 index-regressed anomalies in DJF over the equatorial Pacific $5^{\circ} \mathrm{S}-5^{\circ} \mathrm{N}$, including (a) the longitude of the positive precipitation anomaly $\left(P^{\prime}\right)$ center shift, average values of associated (c) positive differences $\left(\Delta P^{\prime}\right)$ over the east and (e) negative differences over the west, (g) the longitude of ENSO-induced sea surface warming contraction, and (h) the associated decrease in its amplitudes $\left(\Delta \mathrm{SST}^{\prime}\right)$. (b),(d),(f) As in (a), (c), and (e), but for vertical velocity $(\omega)$. The black squares represent individual models whose serial numbers can be found in Table 1 . The correlation coefficient and $p$ value are shown in the bottom-right corner of each panel. The red asterisk indicates the four-model median, which does not join the computation of correlation. The longitude of the rising-branch shift is measured using the average longitude difference of the positions where values of the $5^{\circ} \mathrm{S}-5^{\circ} \mathrm{N}$ equatorial mean state of 500 -hPa vertical velocity (Fig. 6a) equal $0,-1, \ldots,-5 \mathrm{~Pa} \mathrm{~s}^{-1}$. 
(a) Long-term mean $\omega$ at $500 \mathrm{hPa}$

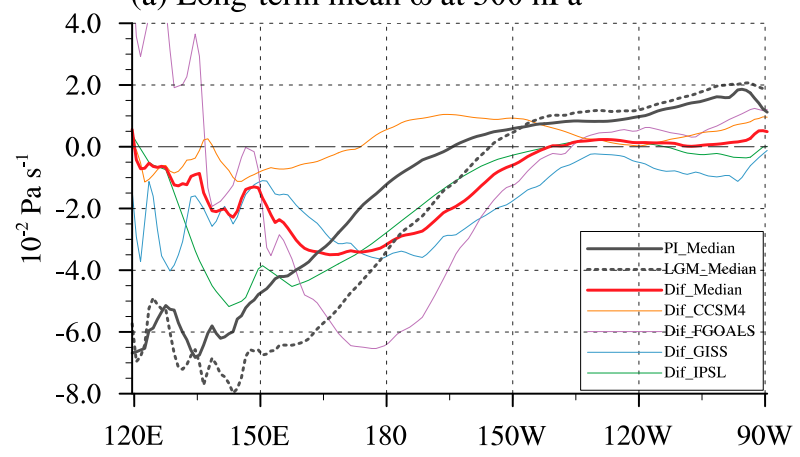

(b) Long-term mean $\mathrm{U}$ at $1000 \mathrm{hPa}$

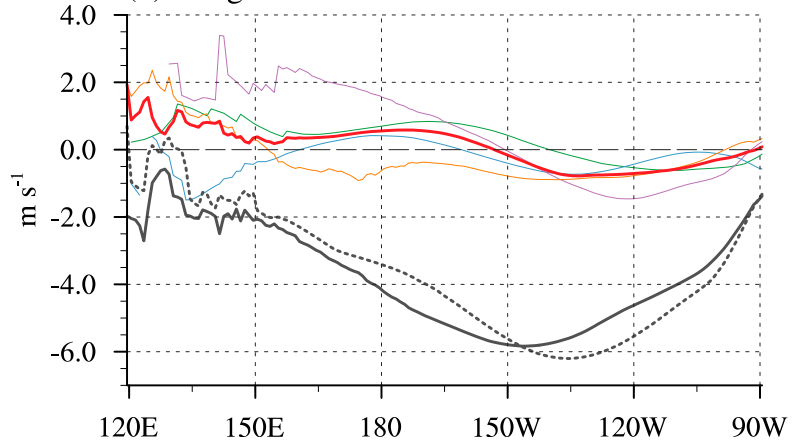

FIG. 6. The profiles of $5^{\circ} \mathrm{S}-5^{\circ} \mathrm{N}$ averages for DJF long-term mean (a) vertical velocity at $500 \mathrm{hPa}$ and (b) zonal winds at $1000 \mathrm{hPa}$. The gray lines indicate mean-state values during the PI or LGM, and colored lines denote LGM minus PI differences for individual models.

DiNezio et al. 2011), respectively. This simulated migration could also be inferred from proxy evidence, including a set of hydroclimatic data exhibiting the lack of drying over northeastern Papua New Guinea and the fresher sea surface salinity in the western equatorial Pacific (DiNezio and Tierney 2013), and a proxy compilation of thermocline temperature showing meridional dipolelike pattern of thermocline depth anomalies in the western Pacific warm pool (Hollstein et al. 2018). In particular, the ascending motion over $180^{\circ}-150^{\circ} \mathrm{W}$ is $-2.0 \times 10^{-2} \mathrm{~Pa} \mathrm{~s}^{-1}$ stronger in the LGM than in the preindustrial period $\left(-0.2 \times 10^{-2} \mathrm{~Pa} \mathrm{~s}^{-1}\right)$, weakening the barrier that prevents convection in this region. Under this condition, even a small increase in SST can significantly alter the atmospheric convections and favor a shift and intensification of precipitation (Bonfils et al. 2015). Accordingly, the altered background vertical motion related to the migration of the climatological Pacific Walker circulation could modify the behavior of tropical convective responses during ENSO events (Fig. 4d), acting as a potential mechanism behind the eastward shift of precipitation anomalies (Fig. 4c).

\section{2) CAUSES FOR CONTRACTION OF ENSO-INDUCED WARMING IN PACIFIC SST}

It has been reported that the mean-state position of the Pacific Walker circulation also has strong linear relations with the wind-SST feedback and heat flux damping feedback, which are the two most important ENSO-related atmosphere-ocean interaction processes (Bayr et al. 2019). In our analysis, the migration of the rising branch has significant positive intermodel correlations at the $95 \%$ confidence level with the contraction distance of ENSO-induced warming in Pacific SST and the related decrease in SST anomalies (Fig. 5). Therefore, the $13^{\circ}$ contraction of the ENSO-induced warm surface anomalies in the equatorial Pacific, as indicated in the median field, is linked to the eastward displacement of the rising branch, and the possible physical processes might be understood by examining changes in background trade winds. The eastward movement of the rising branch favors more precipitation over the western equatorial Pacific (Fig. S8), and as a Gill-type response (Gill 1980), the trade wind weakens to the west of $150^{\circ} \mathrm{W}$ (Fig. 6b). Such a weakening of the westward winds might impede the westward flow of warm water during La Niña and intensify the backflow during El Niño, inducing an eastward contraction of ENSO-induced SST anomalies.

\section{b. Outside the tropics}

\section{1) ENSO-INDUCED ANOMALIES IN ATMOSPHERIC CIRCULATION}

Figure 7 displays the atmospheric circulations associated with the warm phase of ENSO as obtained by regressing the 200-hPa geopotential height and SLP onto the Niño-3.4 index in order to explore the altered responses of precipitation and air temperature outside the tropics. During the preindustrial period, a prominent feature detected in the 200-hPa teleconnection field is the PNA wave train (Wallace and Gutzler 1981; Schneider et al. 2009), manifested by two positive anomaly centers located over northern Canada and the subtropical Pacific, with negative centers over the Gulf of Alaska and the southeastern United States (Fig. 7c). The PNA signal is also discerned in the lower troposphere, and the expression of it involves negative SLP anomalies centered over the Gulf of Alaska and the southeastern United States and positive anomalies over northeastern North America (Fig. 7a), indicating an equivalent barotropic vertical structure of the extratropical response. The aforementioned anomalies in atmospheric circulation give rise to the dipolar pattern of temperature anomalies over North America, with 
(a) PI SLP' \& $850 \mathrm{hPa} \overline{\mathrm{V}}^{\prime}$

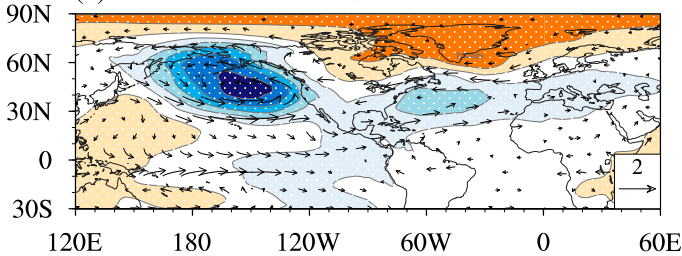

(b) LGM SLP' \& $850 \mathrm{hPa} \overrightarrow{\mathrm{V}}^{\prime}$

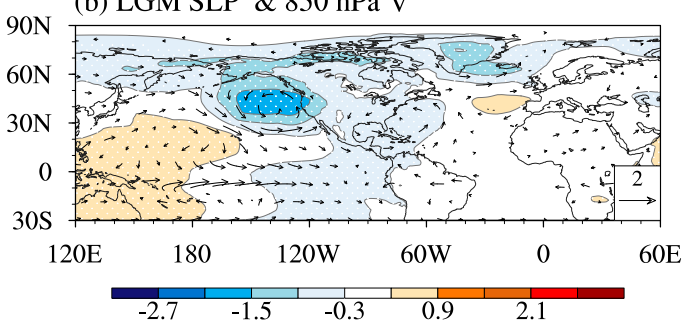

(c) PI HGT' \& WAF $(200 \mathrm{hPa})$

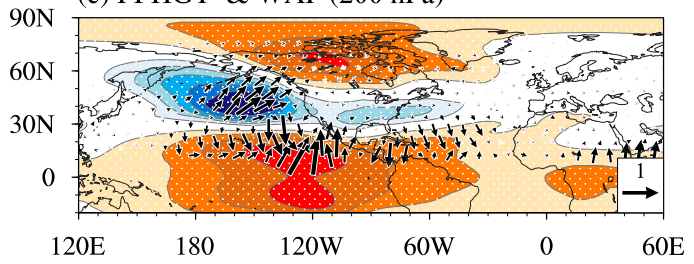

(d) LGM HGT' \& WAF (200 hPa)

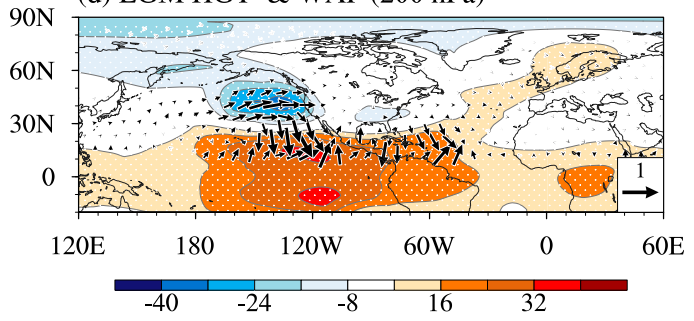

FIG. 7. Regressed anomalies in DJF (a),(b) SLP $\left(\mathrm{hPa}^{\circ} \mathrm{C}^{-1}\right)$ and $850-\mathrm{hPa}$ wind speeds $\left(\mathrm{m} \mathrm{s}^{-1}{ }^{\circ} \mathrm{C}^{-1}\right)$ and (c),(d) geopotential height $\left(\mathrm{m}^{\circ} \mathrm{C}^{-1}\right)$ and vectors of Rossby wave activity flux $\left(\mathrm{m}^{-2} \mathrm{~s}^{-2}{ }^{\circ} \mathrm{C}^{-1}\right)$ at $200 \mathrm{hPa}$, with respect to the DJF Niño-3.4 index. Stippling indicates that at least three out of four models agree on the sign.

warmer conditions in the north and colder conditions in the south (Fig. 3b2). Anomalous southerly winds transport warm moist air and thus enhance precipitation along the west coast of North America (Fig. 3b1). In addition, the PNA pattern intensifies the Pacific jet stream, which even extends farther east than normal toward the southern tier of the United States, amplifying the winter storm activity and consequent precipitation (Fig. 3b1).

During the LGM, it is evident that the ENSO teleconnection amplitude is prominently attenuated. The North Pacific anomaly center weakens by $41 \%$, and the centers over northern Canada and the southern United States almost disappear (Fig. 7d), resulting in the decreased amplitudes of precipitation and temperature responses to ENSO events (Fig. 3). This result is qualitatively consistent with Merkel et al. (2010), who reported a suppression of extratropical ENSO teleconnections in the Northern Hemisphere during the LGM compared to the preindustrial period. In addition, the anomaly centers over the North Pacific and northern Canada move eastward, with values fo $12^{\circ}$ and $20^{\circ}$ as indicated by the multimodel medians, respectively, accounting for the eastward displacement of the ENSOinduced anomalies in precipitation (Figs. 3b1-3c1) and temperature (Figs. 3b2-3c2) in extratropical regions. This eastward migration is not exhibited in Merkel et al. (2010), who employed the CCSM3, and the same result holds to its next generation, namely the CCSM4 used in our analysis.

The formation of the extratropical teleconnection could be attributed to the propagation of quasi-stationary Rossby waves emanating from the cyclonic perturbation over the North Pacific (Trenberth et al. 1998). Here, a diagnostic of horizontal wave activity flux (Takaya and Nakamura 2001) is applied to examine the propagation features of the ENSO-related PNA wave train. Under the WentzelKramers-Brillouin (WKB) approximation, this flux is in the direction of the local stationary Rossby wave group velocity. The equation of the horizontal flux is written as follows:

$$
W=\frac{p \cos \varphi}{2|\mathbf{U}|}\left\{\begin{array}{c}
\frac{U}{a^{2} \cos ^{2} \varphi}\left[\left(\frac{\partial \psi^{\prime}}{\partial \lambda}\right)^{2}-\psi^{\prime} \frac{\partial^{2} \psi^{\prime}}{\partial \lambda^{2}}\right]+\frac{V}{a^{2} \cos \varphi}\left[\frac{\partial \psi^{\prime}}{\partial \lambda} \frac{\partial \psi^{\prime}}{\partial \varphi}-\psi^{\prime} \frac{\partial^{2} \psi^{\prime}}{\partial \lambda \partial \varphi}\right] \\
\frac{U}{a^{2} \cos \varphi}\left[\frac{\partial \psi^{\prime}}{\partial \lambda} \frac{\partial \psi^{\prime}}{\partial \varphi}-\psi^{\prime} \frac{\partial^{2} \psi^{\prime}}{\partial \lambda \partial \varphi}\right]+\frac{V}{a^{2}}\left[\left(\frac{\partial \psi^{\prime}}{\partial \varphi}\right)^{2}-\psi^{\prime} \frac{\partial^{2} \psi^{\prime}}{\partial \varphi^{2}}\right]
\end{array}\right\}
$$

where $p, \psi^{\prime}$, and $\mathbf{U}=(U, V)$ denote the pressure, perturbation of geostrophic streamfunction, and basic state wind velocity, respectively; $\varphi$ is latitude, $\lambda$ is longitude, and $a$ is the radius of Earth. During the preindustrial period, the flux originates in the North Pacific and follows the great circle route, initially extending northeastward to northwestern North America and then curving southward (Fig. 7c). However, during the LGM, 

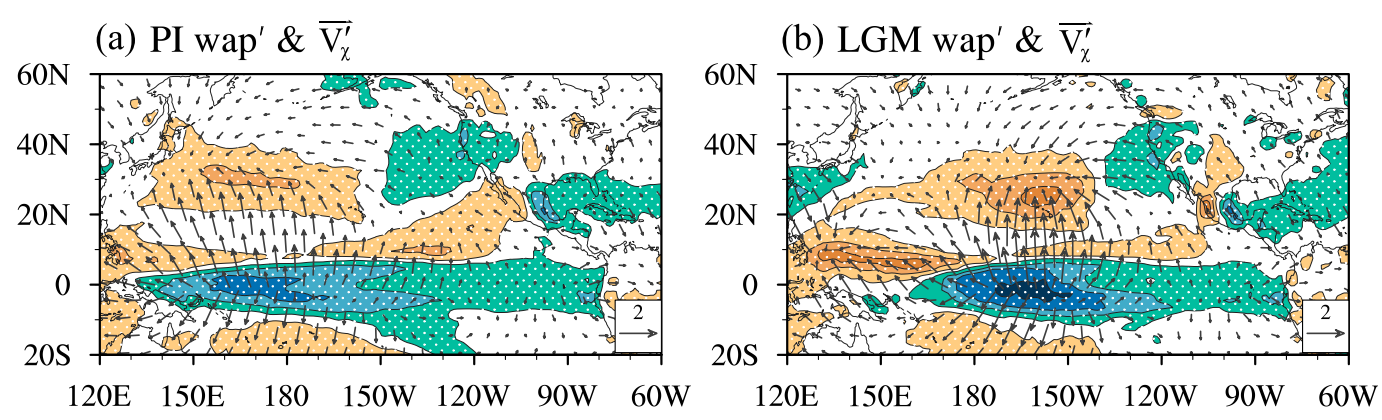

\section{$\begin{array}{lllllllll}-3.4 & -2.4 & -1.4 & -0.4 & 0.4 & 1.4 & 2.4 & 3.4 & \times 10^{-2}\end{array}$}

(c) Static stability

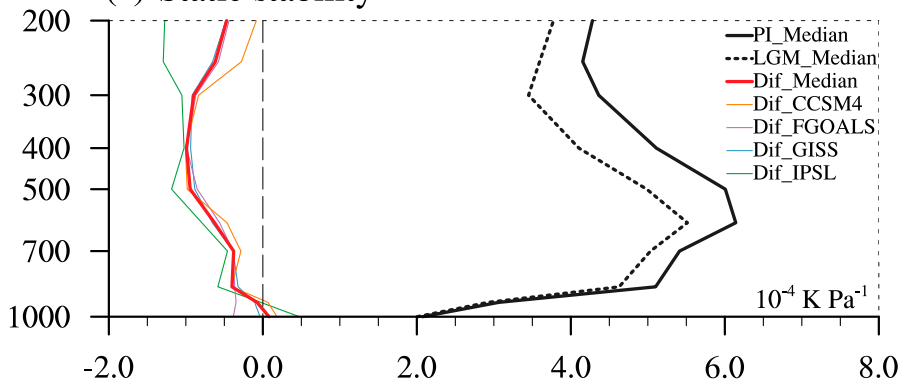

FIG. 8. (a),(b) Spatial distribution of regressed anomalous $500-\mathrm{hPa}$ vertical velocity $\left(\mathrm{Pa} \mathrm{s}^{-1}{ }^{\circ} \mathrm{C}^{-1}\right)$ and $200-\mathrm{hPa}$ divergent winds $\left(\mathrm{m} \mathrm{s}^{-1}{ }^{\circ} \mathrm{C}^{-1}\right)$ in DJF with respect to the DJF Niño-3.4 index. (c) Vertical profiles of the DJF longterm mean of atmospheric static stability $\left(\mathrm{K} \mathrm{Pa}^{-1}\right)$ over the tropical Pacific $\left(5^{\circ} \mathrm{S}-5^{\circ} \mathrm{N}, 150^{\circ} \mathrm{E}-90^{\circ} \mathrm{W}\right.$; gray lines for mean states during the PI or LGM and colored lines for LGM minus PI differences). Stippling in (a) and (b) indicates that at least three out of four models agree on the sign.

the group energy weakens, disperses only toward the east, and dissipates rapidly (Fig. 7d), corresponding to the prominently subdued feature of anomaly centers over North America.

\section{2) TropicAl Forcing AND Rossby WAVE SOURCE}

One factor that directly affects the strength and location of the extratropical teleconnection is the tropical forcing, which takes the form mainly as latent heat release of convective precipitation. For large-scale tropical circulation, diabatic heating is balanced by rising motion, with large divergence in the tropical upper troposphere (Hoskins and Karoly 1981; Holton 1992), which can lead to extratropical subsidence and associated convergence aloft (Figs. 8a,b) through disturbing the Hadley circulation (e.g., Rasmusson and Mo 1993). Therefore, heat-induced vertical motion is a critical factor in the way by which tropical forcing triggers extratropical perturbations. The aforementioned thermodynamic energy balance can be written as follows:

$$
\omega=-\frac{Q}{S_{P}}
$$

where $S_{p}$ is the static stability, and $Q$ denotes diabatic heating proportional to precipitation. Equation (3) implies that the change in vertical motion magnitude is determined by the combined effects of precipitation and static stability. Compared to the preindustrial period, the tropical static stability decreases across the vertical profile (Fig. 8c), in accordance with previous investigations that report a steeper lapse rate (Loomis et al. 2017; Liu et al. 2018). The decrease in static stability amplifies the heating-induced rising motion whose peak amplitude varies by $25 \%$, as indicated by the median field (Fig. 8b), even though the change in peak precipitation anomalies is small $(8 \%)$. In terms of the location, the center of ENSO-related anomalies in rising motion shifts $17^{\circ}$ eastward compared to the preindustrial period (Figs. 8a,b), directly linked to the $15^{\circ}$ displacement of precipitation anomalies to the east [Figs. $3 b(1)-3 c(1)]$. Correspondingly, the anomalous divergent winds at $200 \mathrm{hPa}$ in the tropics and anomalous descending motion with upper-level convergence outside the tropics also intensify and shift eastward.

The way that tropical vertical motion affects extratropical teleconnection circulations can be addressed by examining the Rossby wave source (RWS), which 
(a) PI total RWS

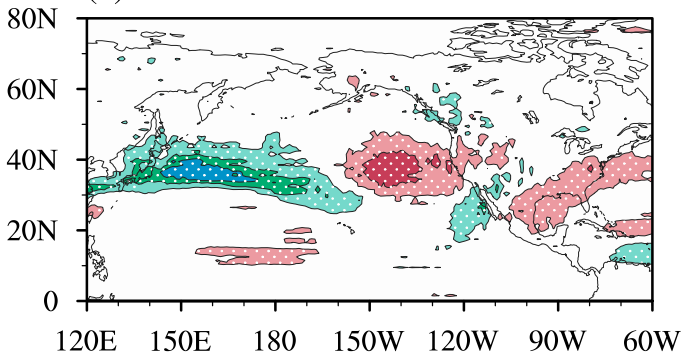

(b) PI Vortex stretching

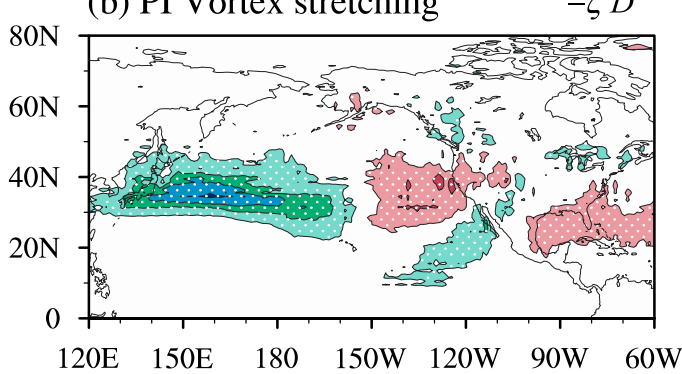

(c) LGM total RWS

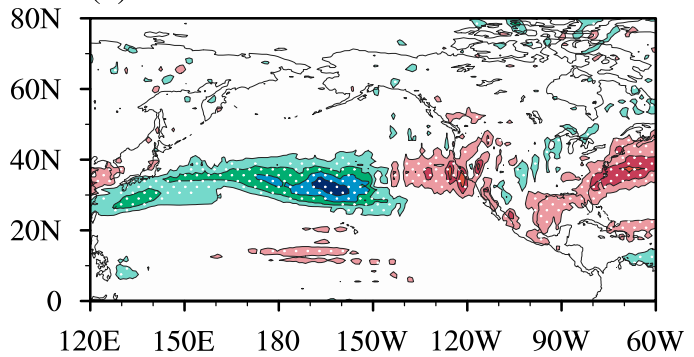

(d) LGM Vortex stretching $-\bar{\zeta} D^{\prime}$

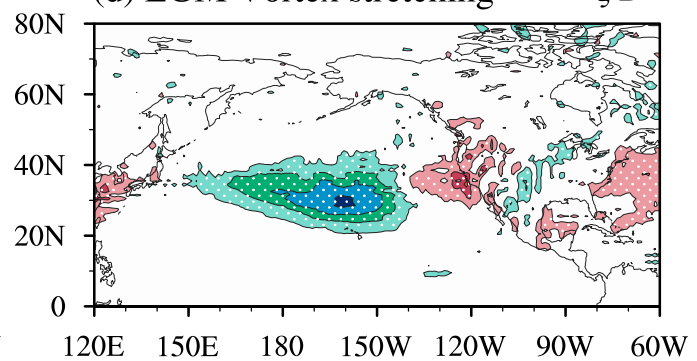

\section{$\begin{array}{lllllllll}-11 & -8 & -5 & -2 & 2 & 5 & 8 & 11 & \times 10^{-11}\end{array}$}

FIG. 9. ENSO-induced (a),(c) total Rossby wave source $\left(\mathrm{s}^{-2}{ }^{\circ} \mathrm{C}^{-1}\right)$ and (b),(d) its vortex stretching component $-\bar{\zeta} D^{\prime}$ calculated at $200 \mathrm{hPa}$ in DJF. Stippling indicates that at least three out of four models agree on the sign.

represents the generation of vorticity forcing. According to the barotropic vorticity equation, the RWS is calculated at $200 \mathrm{hPa}$ as follows (Sardeshmukh and Hoskins 1988):

$$
\mathrm{RWS}^{\prime}=-\bar{\zeta} D^{\prime}-\zeta^{\prime} \bar{D}-V_{\chi}^{\prime} \cdot \nabla \bar{\zeta}-\bar{V}_{\chi} \cdot \nabla \zeta^{\prime}
$$

where $V_{\chi}, \zeta$, and $D$ indicate divergent winds, absolute vorticity, and divergence, respectively; the prime denotes ENSO-induced perturbation; and the overbar represents the background states. The RWS arises from two components, the vortex stretching component (the former two terms on the right side of the equation) linked to the convergence aloft in the extratropics, and the vorticity advection (the latter two terms) by the divergent component of flow. Figure 9 shows that the anomalous RWS related to the ENSO teleconnection is mainly present in the western North Pacific poleward of $20^{\circ} \mathrm{N}$. The magnitude and spatial distribution of total anomalous RWS are greatly similar to that of its component $-\bar{\zeta} D^{\prime}$, while other components are remarkably small (Fig. S9), meaning that the stretching term $-\bar{\zeta} D^{\prime}$ is the dominant factor. The values are small within $20^{\circ}$ of the equator because the magnitude of the mean-state absolute vorticity is limited. More specifically, the way that tropical heatinginduced ascending motion extends its influence into the extratropics is through intensifying the local Hadley cell and giving rise to the extratropical convergence aloft, which accounts for substantial cyclonic forcing in the barotropic vorticity equation and further contributes to the PNA wave train (Held and Kang 1987; Rasmusson and Mo 1993).

In a comparison of the LGM to the preindustrial period, the center of positive RWS anomalies migrates $22^{\circ}$ to the east (Figs. 9c,d), and the intensification of that is slightly increased. Therefore, the changes in RWS are responsible for the eastward shift in PNA activity centers but are not a reason for their attenuation. A further diagnosis indicates that the difference in $-\bar{\zeta} D^{\prime}$ induced by changes in $D^{\prime}$ is one order of magnitude larger than that induced by altered $\bar{\zeta}$ (Fig. S10), implying that the variation in tropical heating that directly causes changes in extratropical upper-level convergence is the ultimate factor leading to the difference in ENSO-related vorticity forcing during the LGM.

\section{3) EFFECTS OF BACKGROUND STATE FLOW}

The background wind field has been recognized as an important factor in governing the path of wave energy propagation in the midlatitudes (Trenberth et al. 1998). Toward addressing the specific effect of the basic flows, the stationary Rossby wavenumber $K_{s}$ (Hoskins and Ambrizzi 1993) is calculated under the Mercator coordinates as follows: 


$$
\begin{aligned}
K_{s} & =\left(\frac{a^{2} \beta_{M}}{U_{M}}\right)^{1 / 2} \\
& =\left\{\left[2 a \Omega \cos ^{2} \varphi-\left(\frac{\partial}{\partial \varphi}\right)^{2}\left(\cos ^{2} \varphi U_{M}\right)\right] / U_{M}\right\}^{1 / 2},
\end{aligned}
$$

where $a$ and $\Omega$ indicate the radius and angular rotation speed of Earth, and $U_{M}$ and $\beta_{M}$ indicate the zonal velocity and the meridional gradient of planetary vorticity in Mercator coordinates, respectively. The propagation of Rossby wave energy tends to be trapped in a tongue of local maximum wavenumber, which is regarded as the waveguide (Schneider et al. 2009). As shown in Fig. 10a, there is a waveguide extending eastward from the Asian subtropical jet and bending into North America, guiding the Rossby wave energy propagating northeastward from the North Pacific into northwestern North America. During the LGM (Fig. 10b), the wavenumber decreases near North America, resulting in a weaker and straighter waveguide. Therefore, the energy propagation path into northern North America is interdicted, consistent with the subdued anomaly center of the PNA pattern there. Based on a set of experiments using CCSM3, $\mathrm{Hu}$ et al. (2020) report that this altered waveguide also leads to a distorted internal PNA mode that develops spontaneously without tropical SST forcing, and they attribute the change to the influence of the blocking of the Laurentide Ice Sheet.

Furthermore, it has been recognized that apart from tropical heating, the inhomogeneity of basic flows is also a significant energy source for the midlatitude perturbation (Simmons et al. 1983; Branstator 1985). The processes of energy exchange between the basic state and perturbation can be expressed by two conversion terms: $-U^{\prime} V^{\prime}(\partial U / \partial y)$ and $-\left(U^{\prime 2}-V^{\prime 2}\right)(\partial U / \partial x)$ (Simmons et al. 1983), with positive values indicating that growing disturbances extract kinetic energy from the basic flow. Figure 11 shows that the North Pacific cyclone lies across the region with positive $-\left(U^{\prime 2}-V^{\prime 2}\right)(\partial U / \partial x)$, which might benefit the growth of eddy energy. The structure of the cyclone is zonally elongated during the preindustrial period and meridionally elongated during the LGM, indicating decreases in $\left(U^{2}-V^{2}\right)$. In addition, the zonal gradients of winds $(\partial U / \partial x)$ weaken in the LGM relative to the preindustrial period, as the Asian subtropical jet weakens, and the westerlies to its east intensify (Fig. S11). Ultimately, there are decreases in $-\left(U^{\prime 2}-V^{\prime 2}\right)(\partial U / \partial x)$ and consequently less energy transport from basic flows to disturbances, which is partly responsible for the subdued extratropical teleconnections. (a) PI wavenumber

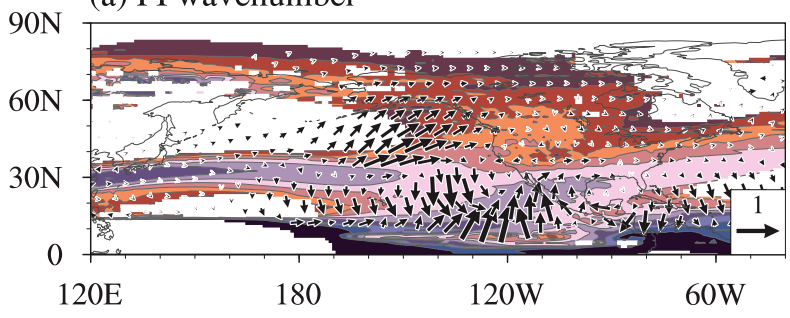

(b) LGM wavenumber

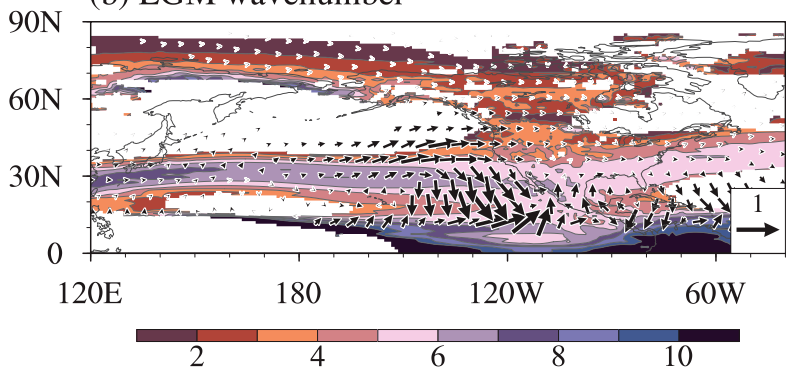

FIG. 10. Multimodel medians of stationary wavenumber (shading) and Rossby wave activity flux (vectors) at $200 \mathrm{hPa}$ for DJF climatology during (a) the PI and (b) LGM periods.

\section{Intermodel consistency}

The weakening and eastward displacement of ENSO impacts are common features in most models, albeit with certain differences in magnitudes and specific locations. For the equatorial Pacific, except CCSM4, the other three models simulate features similar to the median field. Specifically, there are $16^{\circ}-17^{\circ}$ eastward contractions of ENSO-driven sea surface warming (Fig. 2d) and $14^{\circ}-19^{\circ}$ eastward displacements of positive precipitation responses over the tropical Pacific (Fig. 4c) in FGOALS, GISS, and IPSL, indicating substantial intermodel accordance in terms of both direction and magnitude. However, no obvious difference is found in CCSM4 (Figs. 2d and 4c). In the previous section, we have exhibited the ENSO impacts on precipitation and SST depend largely on the position of the mean-state rising branch of the Pacific Walker circulation. Here, the change in the Pacific Walker circulation is not evident for CCSM4 (Fig. 6a), reasonably explaining the indiscernible variation of ENSO impacts; for the other three models, there is high consistency in terms of the magnitude of the rising-branch shift $\left(18^{\circ}-28^{\circ}\right)$, responsible for the intermodel agreement in the migration of ENSO-related variabilities. Furthermore, CNRM5 also suggests qualitatively similar behaviors of the mean-state Walker circulation and ENSO impacts as in the multimodel medians. Considering that LGM reconstructions of hydroclimate (DiNezio and Tierney 2013) and thermocline temperature (Hollstein et al. 2018) implicate an eastward 
(a) $P I-U^{\prime} V^{\prime} \frac{\partial U}{\partial y}$

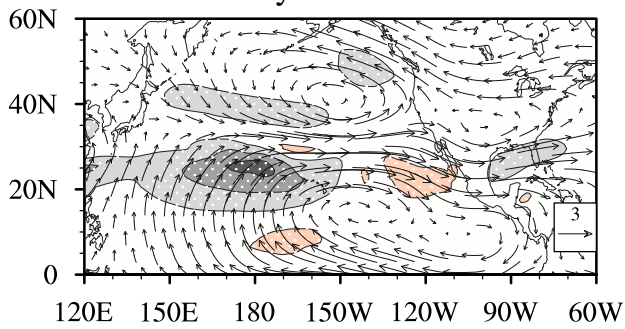

(b) PI - $\left(\mathrm{U}^{\prime 2}-\mathrm{V}^{\prime 2}\right) \frac{\partial \mathrm{U}}{\partial \mathrm{x}}$

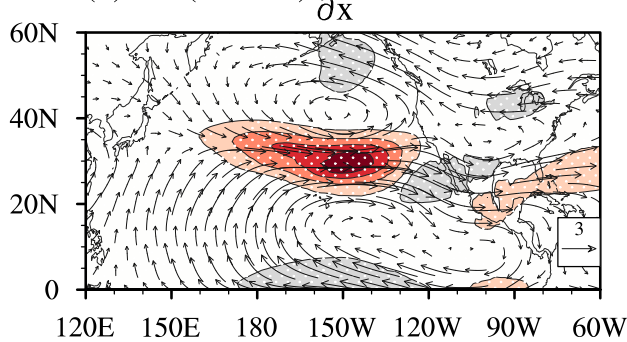

(c) PI - $\frac{\partial \mathrm{U}}{\partial \mathrm{x}}$

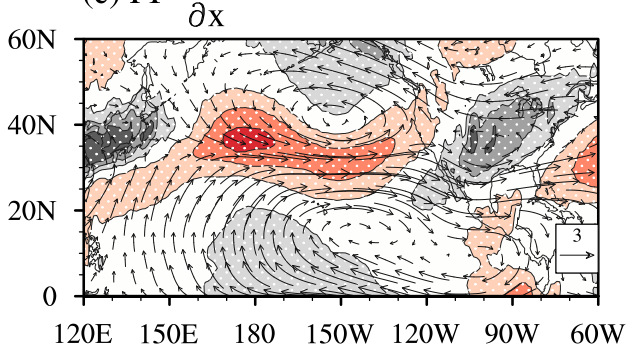

(d) PI $U^{\prime 2}-V^{\prime 2}$

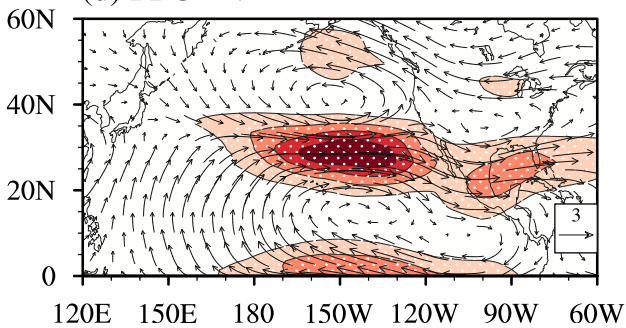

(e) LGM - $U^{\prime} V^{\prime} \frac{\partial \mathrm{U}}{\partial \mathrm{y}}$

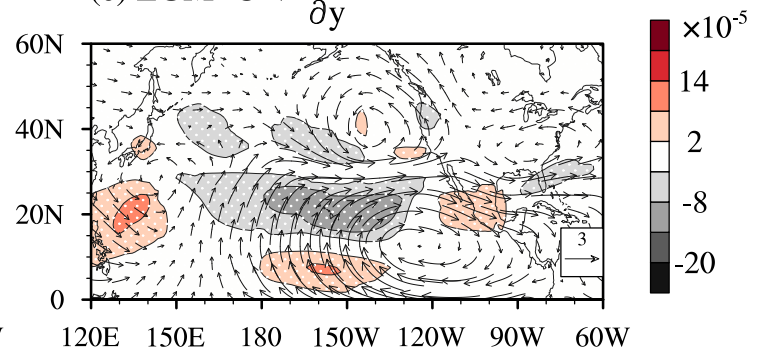

(f) $L G M-\left(U^{\prime 2}-V^{\prime 2}\right) \frac{\partial U}{\partial x}$
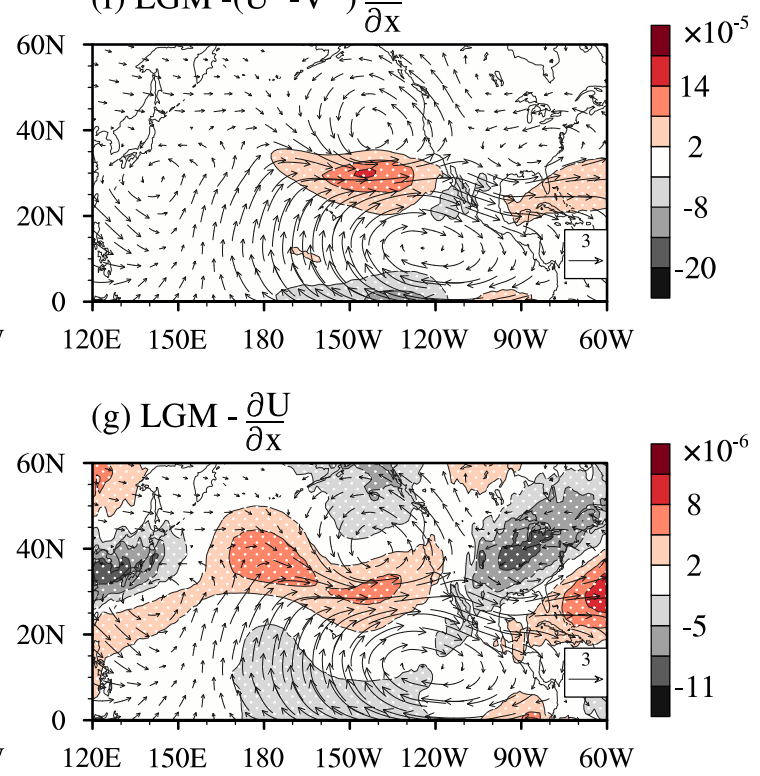

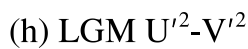

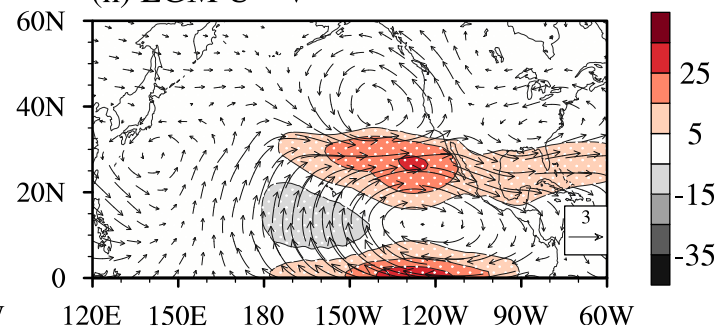

FIG. 11. The energy exchange between the basic state and ENSO-induced perturbation in terms of two conversion terms (a),(e) $-U^{\prime} V^{\prime}(\partial U / \partial y)$ and (b),(f) $-\left(U^{\prime 2}-V^{\prime 2}\right)(\partial U / \partial x)\left(\mathrm{m}^{2} \mathrm{~s}^{-3}{ }^{\circ} \mathrm{C}^{-2}\right)$ in DJF, two components of the latter terms $(\mathrm{c}),(\mathrm{g})-(\partial U / \partial x)\left(\mathrm{s}^{-1}\right)$ and $(\mathrm{d}),(\mathrm{h})\left(U^{\prime 2}-V^{\prime 2}\right)\left(\mathrm{m}^{2} \mathrm{~s}^{-2}{ }^{\circ} \mathrm{C}^{-2}\right)$, and regressed anomalous winds at $200 \mathrm{hPa}$ for the (a)-(d) PI and (e)-(h) LGM periods.

movement of the Pacific Walker circulation on its western side, the CCSM4 might have deviated from the past reality.

In the northern midlatitudes, except CCSM4, there is also an eastward movement over $10^{\circ}$ for the ENSOinduced PNA teleconnection pattern in the other three models (not shown), which corresponds well to the behavior of the regressed tropical precipitation anomalies.
With respect to the amplitudes, the weakening of the extratropical teleconnection is not manifested in only FGOALS-g2, possibly because the variations in tropical peak precipitation responses $(70 \%)$ and related ascending motion $(98 \%)$ are larger than in the other models $(-13 \%-40 \%$ and $5 \%-80 \%)$, meaning that more energy is transferred into the midlatitudes and thus the vorticity forcing is stronger. For other models, there are 


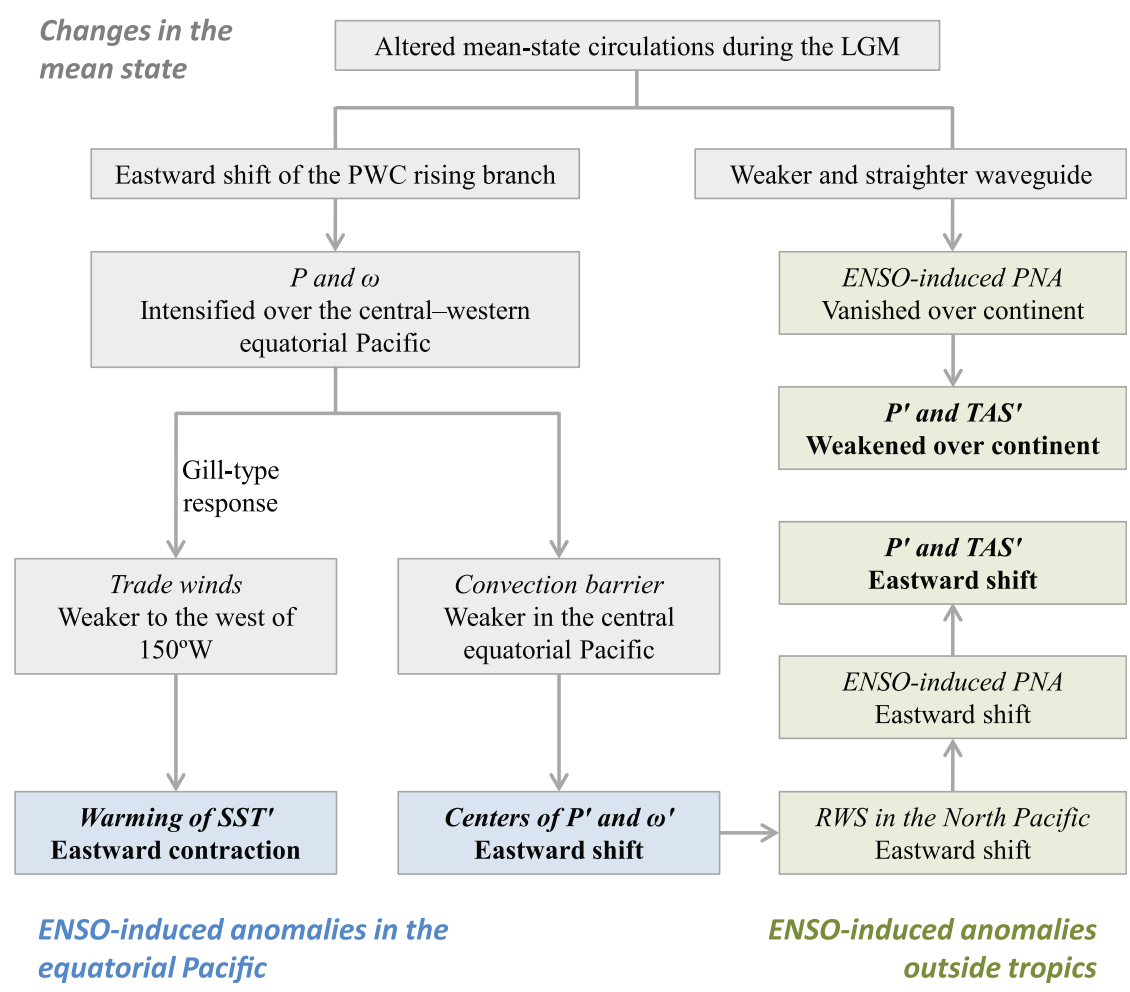

FIG. 12. Schematic diagram illustrating how differences in climatic backgrounds [the Pacific Walker circulation (PWC) rising branch and waveguide] are linked to changes in ENSO impacts.

certain uncertainties concerning reasons for a weakened anomaly center over the North Pacific. Specifically, the RWS is weaker for CCSM4 and IPSL-CM5A-LR, agreeing with weaker responses of the atmospheric circulations; however, there is also a weaker atmospheric response in GISS-E2-R, albeit with a stronger RWS, implying other processes impeding the enhancement of disturbances, such as the interaction with the basic flow that extracts more energy from the disturbances as indicated in the majority of models except FGOALS-g2. Nevertheless, every model agrees that the altered amplitude of tropical forcing, which induces stronger ascending motion in the circumstance of reduced static stability during the LGM, may not be a reason for the weakening. In addition, the decreased wavenumber and the consequent straighter and weaker waveguide near North America are common features for all models, agreeing with the consistent suppression of the activity center over the continent across individual models.

\section{Summary and discussion}

The ENSO impacts over the region $60^{\circ} \mathrm{S}-90^{\circ} \mathrm{N}$, $60^{\circ} \mathrm{E}-60^{\circ} \mathrm{W}$ during the LGM are investigated based on numerical experiments undertaken with models within the PMIP3 framework. Four models (CCSM4, FGOALSg2, GISS-E2-R, and IPSL-CM5A-LR) that reproduce observations are used for our analysis. Main features and possible mechanisms are illustrated in Fig. 12. Compared to the preindustrial period, the ENSO impacts on precipitation and near-surface air temperature are weakened, with average magnitudes of both parameters for the whole region being $-21 \%$ according to multimodel medians. Spatially, the ENSO impacts shift eastward and are attenuated over most regions; only the impacts on equatorial precipitation to the east of the date line are intensified. Over the tropical Pacific, the ENSO-induced sea surface warming contracts $13^{\circ}$ to the east; the positive precipitation anomalies move $15^{\circ}$ eastward, with amplitudes being lower west of the date line and higher to its east. The movement of ENSO impacts is a common feature for the majority of models. The statistical analysis suggests intermodel linear relations ( $95 \%$ confidence level) between such movements of responses to ENSO and the positional changes in the mean-state Pacific Walker circulation rising branch, with the latter moving $16^{\circ}$ eastward as indicated by the median field. The changes in the Pacific perturbation spread along the Walker circulation into other tropical regions, leading to a reduction of climatic sensitivity to 
ENSO. Outside the tropics, there is also an eastward migration of over $10^{\circ}$ in the ENSO-induced PNA teleconnection pattern, which is responsible for the movements of precipitation and air temperature anomalies. Such movements are directly linked to a positional difference in the tropical heating, which takes the form mainly as latent heat release of convective precipitation. Concerning the amplitude, the ENSO-induced PNA pattern is weakened, as manifested by almost vanished activity centers over the North America continent partly due to the weakened waveguide, as well as a diminished North Pacific center whose causes exhibit certain intermodel differences. In the circumstance of reduced atmospheric static stability during the LGM, the tropical heating-induced ascending motion is amplified even in the absence of evident alterations in peak precipitation responses, so the variations in the amplitude of tropical responses to ENSO might not be a reason for the weakened teleconnection outside the tropics.

In conclusion, the relationship between ENSO and climates during the LGM is found to differ from the preindustrial period in terms of the magnitudes and spatial patterns, and the mechanism behind which lies in the difference of background circulations. These conclusions that derived based on the median of four selected models also hold in the median of all models except with smaller magnitudes (Figs. S12-S14). Such a nonstationary relationship is also recognized during the last millennium (Brown et al. 2016) and other glacial periods (Merkel et al. 2010), jointly suggesting that the concept of stationary ENSO impacts should be applied with caution to the reconstructions of past ENSO variability or paleo-ENSO proxy data interpretation. For example, the geological evidence of weaker precipitation variability in New Guinea (Tudhope et al. 2001) might be explained largely by the weakening of the local ENSO signal rather than subdued ENSO activities (Otto-Bliesner et al. 2003). A scale parameter is necessary when quantitative values are required in the reconstruction of ENSO behavior based on the modern relationship. Our analysis reports that the spatial pattern of responses to ENSO events depends on the background state, such as the position of Walker circulation, implying the possibility that the proxy data recording climatological signals could assist in the interpretation of variability-related records. Deeply understanding the linkages between background climates and ENSO-induced variabilities could yield meaningful insights into the reconstructions of ENSO behaviors in the past, and more efforts are required to understand the root dynamical processes rather than being confined to their statistical relations. Note that there are still biases in terms of spatial patterns of the simulated ENSO impacts when compared with the observations, so the modeling results remain difficult to guide data reconstruction in specific locations. Furthermore, our focus is specifically on the canonical ENSO mode, and there is a high possibility that the existing ENSO impacts could be modified by other natural modes of SST viability, such as the ENSO events peaking in the central Pacific (Capotondi et al. 2015; Timmermann et al. 2018). In addition, there exists nonlinear response to different strengths (e.g., Power et al. 2013; Chung et al. 2014) and phases (Timmermann et al. 2018) of ENSO events (Figs. S15 and S16). The issue how these factors might affect the responses to ENSO merits further exploration and research.

Acknowledgments. We sincerely thank the three anonymous reviewers for their insightful comments and suggestions to improve this manuscript. We also acknowledge the NOAA/OAR/ESRL PSD and the Met Office Hadley Centre for providing the reanalysis data, as well as the climate modeling groups (listed in Table 1) for producing and sharing their model outputs. This work is supported by the National Natural Science Foundation of China (41625018), the Strategic Priority Research Program of Chinese Academy of Sciences (XDA20070103), and the National Natural Science Foundation of China (41421004).

\section{REFERENCES}

Adler, R. F., and Coauthors, 2003: The version-2 Global Precipitation Climatology Project (GPCP) monthly precipitation analysis (1979-present). J. Hydrometeor., 4, 1147-1167, https://doi.org/ 10.1175/1525-7541(2003)004<1147:TVGPCP > 2.0.CO;2.

Alexander, M. A., I. Bladé, M. Newman, J. R. Lanzante, N. C. Lau, and J. D. Scott, 2002: The atmospheric bridge: The influence of ENSO teleconnections on air-sea interaction over the global oceans. J. Climate, 15, 2205-2231, https://doi.org/10.1175/15200442(2002)015<2205:TABTIO >2.0.CO;2.

An, S.-I., and B. Wang, 2000: Interdecadal change of the structure of the ENSO mode and its impact on the ENSO frequency. J. Climate, 13, 2044-2055, https://doi.org/10.1175/1520-0442(2000) 013<2044:ICOTSO > 2.0.CO;2.

—, J.-S. Kug, Y.-G. Ham, and I.-S. Kang, 2008: Successive modulation of ENSO to the future greenhouse warming. J. Climate, 21, 3-21, https://doi.org/10.1175/2007JCLI1500.1.

Bayr, T., D. Dommenget, T. Martin, and S. Power, 2014: The eastward shift of the Walker circulation in response to global warming and its relationship to ENSO variability. Climate Dyn., 43, 2747-2763, https://oi.org/10.1007/s00382-014-2091-y.

— D. Domeisen, and C. Wengel, 2019: The effect of the equatorial Pacific cold SST bias on simulated ENSO teleconnections to the North Pacific and California. Climate Dyn., 53, 3771-3789, https://doi.org/10.1007/s00382-01904746-9.

Berger, A. L., 1978: Long-term variations of daily insolation and quaternary climatic changes. J. Atmos. Sci., 35, 2362-2367, https:// doi.org/10.1175/1520-0469(1978)035<2362:LTVODI >2.0.CO;2. 
Bjerknes, J., 1969: Atmospheric teleconnections from the equatorial Pacific. Mon. Wea. Rev., 97, 163-172, https://doi.org/ 10.1175/1520-0493(1969)097<0163:ATFTEP > 2.3.CO;2.

Bonfils, C. J. W., B. D. Santer, T. J. Phillips, K. Marvel, L. R. Leung, C. Doutriaux, and A. Capotondi, 2015: Relative contributions of mean-state shifts and ENSO-driven variability to precipitation changes in a warming climate. J. Climate, 28, 999710 013, https://doi.org/10.1175/JCLI-D-15-0341.1.

Branstator, G., 1985: Analysis of general circulation model seasurface temperature anomaly simulations using a linear model. Part I: Forced solutions. J. Atmos. Sci., 42, 2225-2241, https:// doi.org/10.1175/1520-0469(1985)042<2225:AOGCMS>2.0.CO;2.

Brown, J. R., P. Hope, J. Gergis, and B. J. Henley, 2016: ENSO teleconnections with Australian rainfall in coupled model simulations of the last millennium. Climate Dyn., 47, 79-93, https://doi.org/10.1007/s00382-015-2824-6.

Cai, W., and Coauthors, 2014: Increasing frequency of extreme El Niño events due to greenhouse warming. Nat. Climate Change, 4, 111-116, https://doi.org/10.1038/nclimate2100.

- - and Coauthors, 2015: ENSO and greenhouse warming. Nat. Climate Change, 5, 849-859, https://doi.org/10.1038/nclimate2743.

Capotondi, A., and Coauthors, 2015: Understanding ENSO diversity. Bull. Amer. Meteor. Soc., 96, 921-938, https://doi.org/ 10.1175/BAMS-D-13-00117.1.

Carréric, A., B. Dewitte, W. Cai, A. Capotondi, K. Takahashi, S.-W. Yeh, G. Wang, and V. Guémas, 2020: Change in strong eastern Pacific El Niño events dynamics in the warming climate. Climate Dyn., 54, 901-918, https://doi.org/10.1007/s00382-01905036-0.

Chen, S., S. S. Hoffmann, D. C. Lund, K. M. Cobb, J. Emile-Geay, and J. F. Adkins, 2016: A high-resolution speleothem record of western equatorial Pacific rainfall: Implications for holocene ENSO evolution. Earth Planet. Sci. Lett., 442, 61-71, https:// doi.org/10.1016/j.epsl.2016.02.050.

Chung, C. T. Y., S. B. Power, J. M. Arblaster, H. A. Rashid, and G. L. Roff, 2014: Nonlinear precipitation response to El Niño and global warming in the Indo-Pacific. Climate Dyn., 42, 1837-1856, https://doi.org/10.1007/s00382-013-1892-8

Cobb, K. M., N. Westphal, H. Sayani, E. Di Lorenzo, H. Cheng, R. L. Edwards, and C. D. Charles, 2013: Highly variable El Niño-Southern Oscillation throughout the Holocene. Science, 339, 67-70, https://doi.org/10.1126/science.1228246.

Collins, M., and Coauthors, 2010: The impact of global warming on the tropical Pacific Ocean and El Niño. Nat. Geosci., 3, 391397, https://doi.org/10.1038/ngeo868.

Dai, A., and T. M. L. Wigley, 2000: Global patterns of ENSOinduced precipitation. Geophys. Res. Lett., 27, 1283-1286, https://doi.org/10.1029/1999GL011140.

DiNezio, P. N., and J. E. Tierney, 2013: The effect of sea level on glacial Indo-Pacific climate. Nat. Geosci., 6, 485-491, https:// doi.org/10.1038/ngeo1823.

—, A. Clement, G. A. Vecchi, B. Soden, A. J. Broccoli, B. L. Otto-Bliesner, and P. Braconnot, 2011: The response of the Walker circulation to Last Glacial Maximum forcing: Implications for detection in proxies. Paleoceanography, 26, PA3217, https://doi.org/10.1029/2010PA002083.

Emile-Geay, J., and Coauthors, 2016: Links between tropical Pacific seasonal, interannual and orbital variability during the Holocene. Nat. Geosci., 9, 168-173, https://doi.org/10.1038/ ngeo2608.

Ford, H. L., A. C. Ravelo, and P. J. Polissar, 2015: Reduced El Niño-Southern Oscillation during the Last Glacial Maximum. Science, 347, 255-258, https://doi.org/10.1126/science.1258437.
García-Serrano, J., C. Cassou, H. Douville, A. Giannini, and F. J. Doblas-Reyes, 2017: Revisiting the ENSO teleconnection to the tropical North Atlantic. J. Climate, 30, 6945-6957, https:// doi.org/10.1175/JCLI-D-16-0641.1.

Gill, A. E., 1980: Some simple solutions for heat-induced tropical circulation. Quart. J. Roy. Meteor. Soc., 106, 447-462, https:// doi.org/10.1002/qj.49710644905.

Harrison, S. P., P. J. Bartlein, and I. C. Prentice, 2016: What have we learnt from palaeoclimate simulations? J. Quat. Sci., 31, 363-385, https://doi.org/10.1002/jqs.2842.

Held, I. M., and I.-S. Kang, 1987: Barotropic models of the extratropical response to El Niño. J. Atmos. Sci., 44, 3576-3586, https://doi.org/ 10.1175/1520-0469(1987)044<3576:BMOTER > 2.0.CO;2.

— , and B. J. Soden, 2006: Robust responses of the hydrological cycle to global warming. J. Climate, 19, 5686-5699, https:// doi.org/10.1175/JCLI3990.1.

Hollstein, M., and Coauthors, 2018: Variations in western Pacific warm pool surface and thermocline conditions over the past 110,000 years: Forcing mechanisms and implications for the glacial Walker circulation. Quat. Sci. Rev., 201, 429-445, https://doi.org/10.1016/j.quascirev.2018.10.030.

Holton, J. R., 1992: An Introduction to Dynamic Meterology. 3rd ed. Academic Press, 511 pp.

Horel, J. D., and J. M. Wallace, 1981: Planetary-scale atmospheric phenomena associated with the Southern Oscillation. Mon. Wea. Rev., 109, 813-829, https://doi.org/10.1175/1520-0493(1981) $109<0813$ :PSAPAW $>2.0$. CO; 2 .

Hoskins, B. J., and D. J. Karoly, 1981: The steady linear response of a spherical atmosphere to thermal and orographic forcing. J. Atmos. Sci., 38, 1179-1196, https://doi.org/10.1175/15200469(1981)038<1179:TSLROA > 2.0.CO;2.

- , and T. Ambrizzi, 1993: Rossby wave propagation on a realistic longitudinally varying flow. J. Atmos. Sci., 50, 1661-1671, https://doi.org/10.1175/1520-0469(1993)050<1661: RWPOAR $>2.0 . \mathrm{CO} ; 2$

Hu, Y., Y. Xia, Z. Liu, Y. Wang, Z. Lu, and T. Wang, 2020: Distorted Pacific-North American teleconnection at the Last Glacial Maximum. Climate Past, 16, 199-209, https://doi.org/ 10.5194/cp-16-199-2020.

Huang, P., 2016: Time-varying response of ENSO-induced tropical Pacific rainfall to global warming in CMIP5 models. Part I: Multimodel ensemble results. J. Climate, 29, 5763-5778, https://doi.org/10.1175/JCLI-D-16-0058.1.

— tropical Pacific rainfall variability in a warming climate. Nat Geosci., 8, 922-926, https://doi.org/10.1038/ngeo2571.

IPCC, 2013: Climate Change 2013: The Physical Science Basis. Cambridge University Press, 1535 pp., https://doi.org/10.1017 CBO9781107415324.

Kanamitsu, M., W. Ebisuzaki, J. Woollen, S.-K. Yang, J. J. Hnilo, M. Fiorino, and G. L. Potter, 2002: NCEP-DOE AMIP-II reanalysis (R-2). Bull. Amer. Meteor. Soc., 83, 1631-1644, https://doi.org/10.1175/BAMS-83-11-1631.

Karoly, D. J., 1989: Southern Hemisphere circulation features associated with El Niño-Southern Oscillation events. J. Climate, 2, 1239-1252, https://doi.org/10.1175/1520-0442(1989)002<1239: SHCFAW $>2.0 . \mathrm{CO} ; 2$.

Kim, S. T., W. Cai, F.-F. Jin, A. Santoso, L. Wu, E. Guilyardi, and S.-I. An, 2014: Response of El Niño sea surface temperature variability to greenhouse warming. Nat. Climate Change, $\mathbf{4}$, 786-790, https://doi.org/10.1038/nclimate2326.

Klein, S. A., B. J. Soden, and N.-C. Lau, 1999: Remote sea surface temperature variations during ENSO: Evidence for a tropical 
atmospheric bridge. J. Climate, 12, 917-932, https://doi.org/ 10.1175/1520-0442(1999)012<0917:RSSTVD>2.0.CO;2.

Langenbrunner, B., and J. D. Neelin, 2013: Analyzing ENSO teleconnections in CMIP models as a measure of model fidelity in simulating precipitation. J. Climate, 26, 4431-4446, https:// doi.org/10.1175/JCLI-D-12-00542.1.

Lau, N.-C., and M. J. Nath, 2003: Atmosphere-ocean variations in the Indo-Pacific sector during ENSO episodes. J. Climate, 16, 3-20, https://doi.org/10.1175/1520-0442(2003) 016<0003:AOVITI > 2.0.CO;2.

Leduc, G., L. Vidal, O. Cartapanis, and E. Bard, 2009: Modes of eastern equatorial Pacific thermocline variability: Implications for ENSO dynamics over the last glacial period. Paleoceanography, 24, PA3202, https://doi.org/10.1029/2008PA001701.

Lewis, S. C., and A. N. LeGrande, 2015: Stability of ENSO and its tropical Pacific teleconnections over the last millennium. Climate Past, 11, 1347-1360, https://doi.org/10.5194/cp-11-1347-2015.

Li, J., and Coauthors, 2013: El Niño modulations over the past seven centuries. Nat. Climate Change, 3, 822-826, https:// doi.org/10.1038/nclimate1936.

Li, S., Y. Li, and J. Jin, 2012: Adaptive trimmed mean as a location estimate. J. Syst. Sci. Complex., 25, 973-986, https://doi.org/ 10.1007/s11424-012-1072-7.

Liu, S., D. Jiang, and X. Lang, 2018: A multi-model analysis of moisture changes during the Last Glacial Maximum. Quat. Sci. Rev., 191, 363-377, https://doi.org/10.1016/j.quascirev.2018.05.029.

Loomis, S. E., and Coauthors, 2017: The tropical lapse rate steepened during the Last Glacial Maximum. Sci. Adv., 3, e1600815, https://doi.org/10.1126/sciadv.1600815.

López-Parages, J., B. Rodríguez-Fonseca, and L. Terray, 2015: A mechanism for the multidecadal modulation of ENSO teleconnection with Europe. Climate Dyn., 45, 867-880, https:// doi.org/10.1007/s00382-014-2319-x.

Lu, Z., Z. Liu, J. Zhu, and K. M. Cobb, 2018: A review of paleo El Niño-Southern Oscillation. Atmosphere, 9, 130, https:// doi.org/10.3390/atmos9040130.

McPhaden, M. J., S. E. Zebiak, and M. H. Glantz, 2006: ENSO as an integrating concept in Earth science. Science, 314, 17401745, https://doi.org/10.1126/science.1132588.

Meehl, G. A., and H. Teng, 2007: Multi-model changes in El Niño teleconnections over North America in a future warmer climate. Climate Dyn., 29, 779-790, https://doi.org/10.1007/s00382007-0268-3.

Merkel, U., M. Prange, and M. Schulz, 2010: ENSO variability and teleconnections during glacial climates. Quat. Sci. Rev., 29, 86100, https://doi.org/10.1016/j.quascirev.2009.11.006.

Mo, K. C., and R. W. Higgins, 1998: The Pacific-South American modes and tropical convection during the Southern Hemisphere winter. Mon. Wea. Rev., 126, 1581-1596, https://doi.org/10.1175/ 1520-0493(1998)126<1581:TPSAMA $>2.0$. CO;2

Neelin, J. D., D. S. Battisti, A. C. Hirst, F.-F. Jin, Y. Wakata, T. Yamagata, and S. E. Zebiak, 1998: ENSO theory. J. Geophys. Res., 103, 14261-14 290, https://doi.org/10.1029/97JC03424.

Otto-Bliesner, B. L., E. C. Brady, S.-I. Shin, Z. Liu, and C. Shields, 2003: Modeling El Niño and its tropical teleconnections during the last glacial-interglacial cycle. Geophys. Res. Lett., 30, 2198, https://doi.org/10.1029/2003GL018553.

Philander, S. G. H., 1983: Meteorology: Anomalous El Niño of 1982-83. Nature, 305, 16, https://doi.org/10.1038/305016a0.

Power, S. B., and F. P. D. Delage, 2018: El Niño-Southern Oscillation and associated climatic conditions around the world during the latter half of the twenty-first century. J. Climate, 31, 6189-6207, https://doi.org/10.1175/JCLI-D-18-0138.1.
- - C. Chung, G. Kociuba, and K. Keay, 2013: Robust twenty-first-century projections of El Niño and related precipitation variability. Nature, 502, 541-545, https://doi.org/ 10.1038/nature12580.

Rasmusson, E. M., and T. H. Carpenter, 1982: Variations in tropical sea surface temperature and surface wind fields associated with the Southern Oscillation/El Niño. Mon. Wea. Rev., 110, 354-384, https://doi.org/10.1175/1520-0493(1982)110<0354: VITSST $>2.0 . \mathrm{CO} ; 2$

- and K. Mo, 1993: Linkages between 200-mb tropical and extratropical circulation anomalies during the 1986-89 ENSO cycle. J. Climate, 6, 595-616, https://doi.org/10.1175/15200442(1993)006 <0595:LBMTAE $>2.0 . C O ; 2$.

Rayner, N. A., D. E. Parker, E. B. Horton, C. K. Folland, L. V. Alexander, D. P. Rowell, E. C. Kent, and A. Kaplan, 2003: Global analyses of sea surface temperature, sea ice, and night marine air temperature since the late nineteenth century. J. Geophys. Res., 108, 4407, https://doi.org/10.1029/ 2002JD002670.

Rein, B., A. Lückge, L. Reinhardt, F. Sirocko, A. Wolf, and W. C. Dullo, 2005: El Niño variability off Peru during the last 20,000 years. Paleoceanography, 20, PA4003, https://doi.org/10.1029/ 2004PA001099.

Roy, I., A. S. Gagnon, and D. Siingh, 2018: Evaluating ENSO teleconnections using observations and CMIP5 models. Theor. Appl. Climatol., 136, 1085-1098, https://doi.org/10.1007/ s00704-018-2536-z.

Sardeshmukh, P. D., and B. J. Hoskins, 1988: The generation of global rotational flow by steady idealized tropical divergence. J. Atmos. Sci., 45, 1228-1251, https://doi.org/10.1175/15200469(1988)045<1228:TGOGRF>2.0.CO;2.

Schneider, E. K., M. J. Fennessy, and J. L. Kinter, 2009: A statistical-dynamical estimate of winter ENSO teleconnections in a future climate. J. Climate, 22, 6624-6638, https://doi.org/ 10.1175/2009JCLI3147.1.

Simmons, A. J., J. M. Wallace, and G. W. Branstator, 1983: Barotropic wave propagation and instability, and atmospheric teleconnection patterns. J. Atmos. Sci., 40, 1363-1392, https:// doi.org/10.1175/1520-0469(1983)040<1363:BWPAIA > 2.0.CO;2.

Sohn, B.-J., S.-W. Yeh, A. Lee, and W. K. M. Lau, 2019: Regulation of atmospheric circulation controlling the tropical Pacific precipitation change in response to $\mathrm{CO}_{2}$ increases. Nat. Commun., 10, 1108, https://doi.org/10.1038/s41467-019-08913-8.

Takaya, K., and H. Nakamura, 2001: A formulation of a phaseindependent wave-activity flux for stationary and migratory quasigeostrophic eddies on a zonally varying basic flow. J. Atmos. Sci., 58, 608-627, https://doi.org/10.1175/15200469(2001)058<0608:AFOAPI > 2.0.CO;2.

Taylor, K. E., 2001: Summarizing multiple aspects of model performance in a single diagram. J. Geophys. Res., 106, 71837192, https://doi.org/10.1029/2000JD900719.

, R. J. Stouffer, and G. A. Meehl, 2011: A summary of the CMIP5 experiment design. PCMDI, 33 pp., http://cmippcmdi.llnl.gov/cmip5/docs/Taylor_CMIP5_design.pdf.

- — - and — 2012: An overview of CMIP5 and the experiment design. Bull. Amer. Meteor. Soc., 93, 485-498, https:// doi.org/10.1175/BAMS-D-11-00094.1.

Thompson, D. M., and Coauthors, 2017: Tropical Pacific climate variability over the last 6000 years as recorded in Bainbridge Crater Lake, Galápagos. Paleoceanography, 32, 903-922, https://doi.org/10.1002/2017PA003089.

Thompson, L. G., E. Mosley-Thompson, M. E. Davis, V. S. Zagorodnov, I. M. Howat, V. N. Mikhalenko, and P.-N. Lin, 
2013: Annually resolved ice core records of tropical climate variability over the past 1800 years. Science, 340, 945-950, https://doi.org/10.1126/science.1234210.

Tian, Z., and D. Jiang, 2020: Weakening and eastward shift of the tropical Pacific Walker circulation during the Last Glacial Maximum. Boreas, 49, 200-210, https://doi.org/10.1111/bor.12417.

Timmermann, A., and Coauthors, 2018: El Niño-Southern Oscillation complexity. Nature, 559, 535-545, https://doi.org/ 10.1038/s41586-018-0252-6.

Trenberth, K. E., G. W. Branstator, D. Karoly, A. Kumar, N.-C. Lau, and C. Ropelewski, 1998: Progress during TOGA in understanding and modeling global teleconnections associated with tropical sea surface temperatures. J. Geophys. Res., 103, 14 291-14 324, https://doi.org/10.1029/97JC01444.

Tudhope, A. W., and Coauthors, 2001: Variability in the El NiñoSouthern Oscillation through a glacial-interglacial cycle. Science, 291, 1511-1517, https://doi.org/10.1126/science.1057969.

Vecchi, G. A., and B. J. Soden, 2007: Global warming and the weakening of the tropical circulation. J. Climate, 20, 43164340, https://doi.org/10.1175/JCLI4258.1.

Wallace, J. M., and D. S. Gutzler, 1981: Teleconnections in the geopotential height field during the Northern Hemisphere winter. Mon. Wea. Rev., 109, 784-812, https://doi.org/10.1175/ 1520-0493(1981)109<0784:TITGHF > 2.0.CO;2.
Wang, B., X. Luo, Y.-M. Yang, W. Sun, M. A. Cane, W. Cai, S.-W. Yeh, and J. Liu, 2019: Historical change of El Niño properties sheds light on future changes of extreme El Niño. Proc. Natl. Acad. Sci. USA, 116, 22 512-22 517, https://doi.org/10.1073/pnas.1911130116.

Watanabe, T., and Coauthors, 2011: Permanent El Niño during the Pliocene warm period not supported by coral evidence. Nature, 471, 209-211, https://doi.org/10.1038/nature09777.

Yang, S., Z. Li, J.-Y. Yu, X. Hu, W. Dong, and S. He, 2018: El NiñoSouthern Oscillation and its impact in the changing climate. Natl. Sci. Rev., 5, 840-857, https://doi.org/10.1093/nsr/nwy046.

Yeh, S.-W., and Coauthors, 2018: ENSO atmospheric teleconnections and their response to greenhouse gas forcing. Rev. Geophys., $\mathbf{5 6}$, 185-206, https://doi.org/10.1002/2017RG000568.

Yu, J.-Y., and H.-Y. Kao, 2007: Decadal changes of ENSO persistence barrier in SST and ocean heat content indices: 19582001. J. Geophys. Res., 112, D13106, https://doi.org/10.1029/ 2006JD007654.

Zhang, Q., Y. Guan, and H. Yang, 2008: ENSO amplitude change in observation and coupled models. Adv. Atmos. Sci., 25, 361366, https://doi.org/10.1007/s00376-008-0361-5.

Zhou, Z.-Q., S.-P. Xie, X.-T. Zheng, Q. Liu, and H. Wang, 2014: Global warming-induced changes in El Niño teleconnections over the North Pacific and North America. J. Climate, 27, 9050-9064, https://doi.org/10.1175/JCLI-D-14-00254.1. 